\title{
Immune Functional Capability Dynamics Determine Disease Outcomes as in Cancer, Heart Diseases, COVID-19, Etc.
}

Jianqing $\mathrm{Wu}^{1}$, Ph.D., J.D. and Ping Zha ${ }^{2}$, M.D. (Chi. Med.)

Date written: August 2, 2021 (a first draft v100).

Last updated October 5, 2021 (v102)

This article is available for download from the website it hosts and there is no need to request for preprint.

Correspondence: tempaddr2@atozpatent.com

1. Healthier World, P. O. Box 689, Beltsville, MD 20704. www.igoosa.com.

Keywords: human immune system dynamics, immune functional fluctuations, multiple factor health optimization, reductionist limitations, incurable diseases, cancer and COVID-19

\begin{abstract}
Having proved flaws in using clinical trials to study weak factors, we want to investigate how life factors affect health and diseases. In this study, we show that cancer, heart disease and infectious diseases are inherently preventable and curable. We would like to find how life factors revolving around environment, emotion, personal activity, disease agents, diets, behaviors, etc. affect disease outcomes. We expand the scope of the immune functions to include functions for removing garbage and repairing tissue damages, and then identify six classes of health properties for evaluating the immune system's actual functional capabilities. In this model, personal ability to resist infection depends on the immune system's current functional capabilities, and the ability to resolve existing diseases depends on the immune system's actual functional capabilities integrated over a relevant time. We show how each life factor affects the immune system's current functional capabilities by examining its effects on any of the six classes of properties. Many seemingly irrelevant life factors can affect disease outcomes because they share biological resources for removing garbage, repairing tissue damages and maintaining all vital functions. Thus, we found that rational strategies for conquering diseases are identifying disease causes, avoiding exposure to
\end{abstract}


disease agents, detoxifying toxic substances, and using seemingly-irrelevant life factors to boost real-time immune functional capabilities and vital organ functions. All chronic diseases including personal resistance to SARS-CoV-2 are influenced by $\mathrm{N}$ and $\mathrm{M}$ factors, where $\mathrm{N}$ represents the number of factors closely related to disease causes, and $M$ represents the number of factors that influence the immune functional capacities and organ capacities. Most of $\mathrm{N}$ factors are pollutants (in a broad sense) while most of $\mathrm{M}$ factors are social practices that are formed after the Industrial Revolution, particularly modern era. This model implies the need to address massive toxic substances and examine health-ruining social practices in education, employment, business, litigation, promotion, etc.

\section{INTRODUCTION}

In our first article [1], we show that weak lifestyle factors cannot be studied as long as other weak factors interfere with the measurement. We first found that the mean of $\mathrm{N}$ weak factors could be $\mathrm{N}$ times of the mean of a single factor. In this study, we used a unique method of proof: we constructed two kinds of trials by assuming effects of a single treatment or multiple-factor treatment by using the same assumptions that would routinely be used in medical research, we then determined whether the research model could correctly find the assumed treatment effects. It cannot. In this study, we have not challenged all key presumptions.

We found that a fatal flaw is mathematical operation to get an averaging effect of weak factors. For example, the nutritional status of any nutrient and a toxic substance is unique in each person. If a treatment for correcting malnutrition or a toxic substance is randomly applied to all people in a treatment group, its true beneficial effects on some patients can be "nullified" by their negating or adverse effects on other patients. This means that a negative finding in a clinical trial does not guarantee it is actually harmful to all people. What is told is that such a treatment is harmful to more people than beneficial to others. The outcome is just the numeric mean which happens to be on the negative side, as compared with the control. In an optimization trial to determine effects of many weak factors, all controllable factors are used as part of the treatment and are used only on the persons who need them. We should predict that the treatment of using 100 factors could deliver 100 times of a single factor (assuming each of them has the same amount of benefit). However, many factors have both positive effects and negating effects in both the treatment and the control in the clinical 
trial, its net weak effect may appear to be zero (e.g., a zero mean in the treatment and a zero mean in the control). That does not mean that the factors have really no effect on all subjects. However, if each of hundreds of factors is correctly used (so that excessive substance is reduced and deficient nutrient is added), the mean of one hundred factors could be more than 100 times of the single factor. Population medicine made a wrong assumption that all people are similar, but in reality they are not.

The second fatal flaw in clinical trails is that most studies attempt to bundle all weak factors into the experimental error. This is permissible if the weak factors are really weak or in a clinical trial for studying a super strong treatment like surgeries and pain killers, but may not be relied to rule out the real benefits of weak factors. We found that the expected statistics would be enlarged by $\mathrm{k}^{*} \sqrt{\mathrm{k}}$, where $\mathrm{k}$ is the number of weak factors. If the total number of weak factors is increased from 1 to 2, 5, 10, and 100, the treatment statistics would increase by $2.8,11.2,32$, and 1000 times. This means that bundling weak effects as an error is improper for studies that require high accuracy. The multiplication factors for T statistic, $\mathrm{Z}$ statistic, and $\mathrm{F}$ statistic is $(1 / \mathrm{g}) \mathrm{k} * \sqrt{\mathrm{k}}$, where $\mathrm{g}$ is a value that depends on whether each factor matches each person. In conclusion, the current research model is clearly incompetent for studying chronic diseases.

We further found that "When the apparent "error" is far too large, relative to the effects of the treatment, data set tends to come out with test statistics falling on the region of acceptance of the null hypothesis, thus resulting in false acceptance of the null hypothesis or false rejection of true treatment effects. Those fatal flaws are expected to exist under most circumstances. No statistical method, no any other methods under the Sun, can ever correct this great bias that arises from breaching the core presumption used in the statistical model. Thus, clinical trials are invalid and have been misused in studying chronic diseases."

In our second study [2], we deeply examined the presumptions that are used in the medical research model and we found that all key presumptions do not hold. We further found that statistical observations must have values representing a property that is fully defined and cannot be changed during a trial. In clinical trial, data could be freely swapped between any two members within a treatment group. In the worst scenario, a finding of $50 \%$ effectiveness rate could be found on two completely different groups of people. To doctors or government, saving these 50 persons or those 50 persons among the total one hundred persons are same, but the outcomes have completely different consequences to the patients. The same conclusion and the $\mathrm{P}$ statistical significance level mean 
completely different things to different persons. In population medicine, saving John Dole and losing Lisa Doe are same as losing John Doe and saving Lisa Doe. By focusing on one single conclusion with a significant level, the population model is unable to address personal differences. Thus, treatments from a best population outcome may not work for specific persons.

To further explore the flaws in clinical trials, we examined four presumptions, and found, among others, that statistical population of health properties simply does not exist for most research purposes, mathematical models are misused to model intensive properties, and reductionist treatments are inferior and inherently dangerous [2]. The lack of distribution and impermissible data summation are fatal, rendering most medical research conclusions meaningless.

One big flaw is use of mathematical operations to cross different systems (e.g., different persons). While mathematics allows one to add any numbers up to get average, there are many restrictions in reality. The numbers must be in the same unit, scale, and have similar significance. Extensive properties such as mass and volume are additive if they concern same matter or volume and mass are the only important things. One class of properties is intensive property that reflects the physical property of a system. Examples of intensive properties include temperature, pressure, refractive index, density, etc. Temperature at one system and temperature at another system are not additive because heat represented by any temperature range are different, and temperature at DIFFERENT SYSTEMS such as water and gas means completely different things. All health properties (except weights and volumes) are similar to intensive properties that must be tightly confined to the system (e.g., the person).

The flaw of cross-system modeling can be seen by considering a car model. A Civic uses fuel at the rate of 1 gallon/time (where time is a suitable time unit) and an Accord consumes fuel at the rate of 2 gallons/time. Their average, 1.5 gallons/time, may indicate the average fuel usage, which is useful only in determining fuel supply and demand. However, this number cannot be used to study the performance of both the cars because the performance of each car depends on a large number of related variables such as car weight, carried goods, driving distance and speed, etc. The average, $1.5 \mathrm{gal} /$ time, has no meaning if it is viewed out of the context. We found, for example, that average of heart output of a 180$\mathrm{lb}$ man and the heart output of a $90 \mathrm{lb}$ woman has no meaning because the average can be applied to neither the man nor the woman. We should see that all disease properties cannot be summed and averaged among different persons. While studies involving different persons data may be useful for other purposes such as 
housing, food supply, etc, they cannot be used as the basis for validating or rejecting a treatment.

Based on our previous studies, we want to prove how weak factors such as lifestyle, dietary, emotional, disease agents, and environmental factors affect health and chronic diseases. While tens of thousands of studies have provided irrefutable evidence to establish our multiple disease causes model, which blur differences between causal factors, associated factors, risk factors, non relevant factors, etc, we want to prove that all weak factors affect personal health and disease outcomes. In this study, we will explore the immune system's dynamics and show that how personal life factors affect personal health and disease outcomes and why their effects can be added.

\section{CHRONIC DISEASES ARE AMENDABLE TO LIFE FACTORS}

It is indisputable that predictable cures are not available in medicine [3-9]. We have witnessed on-going HIV epidemic and the cancer epidemic [10-13], and now the COVID-19 pandemic [15]. Each of those diseases has become a global health crisis. Medicine attributes AIDS mainly to the HIV virus, cancers to genetic mutation, and the COVID-19 to the SARS-CoV-2 virus, but has not focused on personal lifestyle factors and personal life activities. We show that several major diseases can self-resolve, heal naturally, or be amendable to a large number of life factors below.

\section{A. Cancer Spontaneous Resolution Miracles}

It is indisputable that cancer can heal naturally as in hundreds of documented cases [16-44] and perhaps millions of undocumented cases [a reasonable assumption]. The spontaneous resolution of cancer is known for hundreds to potentially thousands of years [44]. It is now accepted as an indisputable fact. Past literature demonstrates that cancer regression is usually associated with acute infections, fever, and immunostimulation. More recent study found that cancer can be prevented by major change of lifestyle [45]. However, medicine uses chemotherapy and surgeries as the primary treatments even though the cancer somatic mutation theory [46] is largely irrelevant to most cases [47] and the performance of those measures is generally poor [14, 47-49]. A large number of recent studies show that cancer is a disease aggravated by pollutants, mental stress, and a fault lifestyle [50-65]. 


\section{B. AIDS Virus Is Not Always Transmitted.}

AIDS is clearly associated with heavy metals [66], toxic chemicals and substances [66-68] and a large number of environmental, ecological, social and economical factors [68]. HIV does not always transmit within couples [69-71]. One study [70] found the discordant couples among 768 families are 8.3\% (where the rate with husband+ and wife- is $4.9 \%$ and the rate with husbandand wife+ is $3.4 \%$ ). The study found that concordant couple (husband+, wife+) rate is only $2.3 \%$. The other all-negative concordant rate (husband- and wife-), $89.4 \%$, does not prove transmission between couples. Among the $10.6 \%$ of the couples with at least one infected spouse, only about $22 \%$ of them may have transmitted the virus (assuming that all second spouses in those couples always acquire the HIV from the first infected spouse) while no transmission has happened among the $78 \%$ of couples. While conscious avoidance of physical contact may be a factor that is not revealed in research, the data at least show that HIV is not highly transmissible among couples as society has perceived.

HIV discordant couples seem fairly often in society. One example is reported in a popular media [69]; such cases cast even more doubt on the damaging effects of the HIV virus on patients. The massive post-2000 research findings of the roles of a large number of immune suppressants cast even a bigger doubt on the virulence of the HIV virus. Our multiple disease causes model, existence of the massive number of immune suppressants, and the large number of discordant HIV couples are considered together, we must conclusively refute that the notion that HIV is the sole cause of AIDS. If medicine finally accepts the view that the HIV is merely a passenger virus at least in most cases, cures for AIDS lie in a different domain [68]. If alteration of the immune system is a requisite for developing AIDS, the attempt to find HIV vaccine must fail because all vaccines are intended to speed up immune responses. The long failure to find HIV vaccine reasonably suggests there might be subtle alterations in the immune systems of AIDS patients.

\section{Heart Diseases}

It is a long-standing position of American Heart Association that nearly $90 \%$ of heart diseases could be presented. A large number of factors affect this disease [72-77]. The disease could be prevented or cured by dietary modification [73-74], stress management [75-76], and exercise [78]. We have seen a large number of research findings that could conclusively establish that vascular diseases can be prevented and mitigated by altering a large number of lifestyle factors and personal activities. One estimate suggested that if the U.S. population dropped its sodium intake to $1,500 \mathrm{mg} /$ day, overall blood pressure 
could decrease by $25.6 \%$, with an estimated $\$ 26.2$ billion in health care savings and another estimate projected that achieving this goal would reduce vascular disease deaths by anywhere from 500,000 to nearly 1.2 million over the next decade [73]. We note most of those measures are outside medical treatments. The poor ability to contain this global epidemic is clearly due to the narrower options. If a person uses a large number of measures, the chance of preventing and healing heart diseases must be much higher.

\section{COVID-19 Is Not A Deadly Disease for Most People}

It is well known that nearly $80 \%$ of people develop mild or little symptom after they are infected by SARS-CoV-2 virus. This fact indicates that the human immune system plays a big role. Our study found that a century of medical findings collectively imply that COVID-19 disease is aggravated by loaded toxic substances in the human body $[66,67,80]$ and a large number of other factors [79-100]. Many toxic substances are known [104]. Well known risk factors also suggest that this disease can be avoided or mitigated by eliminating those risks factors [210]. In addition, this disease is highly sensitive to temperature and climate [121].

\section{DYNAMIC NATURE OF THE IMMUNE SYSTEM}

We need to make an assumption that human ability to counter chronic diseases and infection diseases finally lies in the immune system. Cancer self resolution takes place due to restoration of the immune system, and the ability to clear infectious agents is finally rested on the immune system. We limit the notion that medicine can cure diseases to only diseases of acute nature. Before we present our methodology, we need to consider all functions of the immune system.

\section{A. Expand the Functional Definition of the Human Immune System}

A multiple cell organism must repair damage in any part of tissue and maintain tissue integrity. Immune functions include more than the classical tasks of killing or removing foreign agents. They include other functions such as patrolling functions [106-107], garbage removal [105], tissue repairing, wound healing, and tissue structural remodeling as in cancer [110-112]. Moreover, they

may include functions for destroying different pathogens [108], and the ability to protect immune cells [109]. Garbage removal and tissue repairing functions may be much more important than they are understood in literature. 
Research findings have revealed two classes of effects on the immune system. Some immune suppressing factors can alter cell structures in a permanent nature. There are a large number of such factors; and they can cause permanent changes in the vascular system, particularly, the micro vascular networks. Permanent changes (as shown in FIG. 1) in the immune system cannot be easily restored. The second classes of effects are immediate effects which may be caused by presence of chemicals, irons, particles, etc. They work by directly interfering with biochemical reactions of immune responses. The SARS-CoV-2 virus may make entries in a matter of an hour. Whether a person can prevent the disease, this current functional capacity of the immune system is more important than the average capacity or imagined maximum capacity of his immune system. Since the immune functional capacity fluctuates rapidly, immune system's capability to prevent infection cannot be evaluated without considering its current capacities. One strategy for preventing viral entire is to avoid suppression of the immune system in a reasonable time window, during which exposure to the virus occurs.

Since we are interested in exploring the accumulated weak effects of multiple life factors, we must also include all potential interaction mechanisms including the unknown mechanisms. In addition, the scope of factors we consider are very broad, including substances (synthetic chemicals, natural compounds and drugs), environment factors, activities, thinking habits, diet and nutrition, activity timing, etc. It is obvious that a factor may have both permanent effects and immediate effects on the immune system, depending on nature of the factor. We consider the following important points in evaluating emotional functions.

First, it is well known that human ability to ward off diseases declines with age. It has been firmly established that the organ functional capacities decline with age [113-117]. Aging clearly reflects degraded tissue structure which we will find to be the key factor that influences the immune system. The immune system functional capacity in a person declines with age, as shown in FIG. 1.

Second, we stress the importance of the function to remove garbage [105]. Most of biological processes must run nearly at steady state: whenever the balance is disturbed, it will reach a new steady state balance. The immune system must remove wastes originated from infected cells, dead tissue cells, and immune cells. Since the immune functional capabilities change periodically, we must consider their time-dependent effects. The failure to remove garbage must result in tissue swelling, which further impairs blood circulation. Since the tissue removes metabolic wastes at different rates in different times, its overall capability can be represented by the integrated area of the capacity cure over 
time. Both the current capacity and the capacity-time curve are important. In a tissue, cells may die from infection, aging, toxicity damages, etc. Garbage removal function is a shared function. If a toxic substance causes an increased rate of cells deaths, the toxic substance must adversely affect removal of virusinduced dead cells. Even personal activities must affect this vital function.

The immune system must repair the tissue damaged by viral action [110112]. After infected cells and diseased cells are killed and removed, the immune system must repair the tissue. It must generate new cells to form new tissue. Whether tissue damage is caused by virus, toxic substances, aging or immune reactions, it would require similar processes to have the tissue repaired. This function is vitally important. The immune system includes the function to regenerate lost tissue [223-224], and if tissue has developed an abnormal structure, the immune system must remodel it [110-112]. Stem cells researches have provided some hints on correcting damaged tissues. It is generally agreed that resident stem cells, Mesenchymal stem cells, and micrograft stem cells can repair damaged tissues [223-224]. Based on the repairing time window and the need to correct cellular damages, the best source of cells for filling missed tissue could be bone marrows or circulating blood. The stem cells from blood are presumed to be involved in repairing tissues.

We suspect that white blood cells, red blood cells or other cells may be involved in the repair of damaged tissue. Those cells are present in abundant amount, and some of white blood cells are known to change forms upon entering the tissue. It is hard to trace them. It is known that lost tissue voids in a boil or viral infected site can be filled up rapidly. The healing speed is not what tissue resident stem cells would achieve by cell division. From the need to preserve genetic integrity, the best cell source is the bone marrows which are well protected against environmental impacts. If genetic composition of a tissue is damaged, repairing merely by the resident stem cells probably cannot correct genetic changes. Considering those reasons, we hypothesize that plasma stem cells, white blood cells, and even red blood cells would be best cells to fill missed tissue by changing their forms upon signals from the tissue. This would explain the rapid repairing capability in the healing cases. However, no study has traced the white blood cells, red blood cells, etc. to confirm or preclude this possibility. One problem is that it is difficult to study blood cell identities by using animal models or experimental methods because their repairing functions happen only in certain conditions that would not be duplicated outside the body.

In this article, immune functional CAPACITIES mean a system's process speeds, which is a special kinetic parameter. They reflect how fast the immune 
system can find and neutralize foreign antigens, how fast immune cells can migrate in a tissue, how fast the immune system can process metabolic products in an infected tissue or the whole body, and how fast it can repair damaged tissue (e.g., the number of new cells it can produce in a given tissue in a given time). In existing medical studies, immune function is a vague concept. However, since clinical trials and animal studies often conduct treatment-vs-control comparison for a fixed duration, the outcomes of such studies do reflect differences in their process rates. However, most existing studies (as far as they are used to characterize treatments) do not pay attention to the great fluctuations of such functional capacities, but treat them as imagined averages. We note that mean cannot carry full meaning in personal ability to resist diseases. Moreover, immune functions deduced in clinical trials (even if they are expressed as disease outcomes) always involve averaging data from different persons. Our definition is attempted to dramatically improve accuracy by focusing on the time-dependent effects, avoiding averaging data from different persons, and distinguishing immune suppressive factors' permanent effects from their current effects.

Finally, we must stress the interactions between the immune system and organ functions. The failure of the immune system does not reflect on the tissue itself, but always reflect in heart failure or other organs failure. When the immune system fails, tissue damages are not repaired in time, tissue cell organization is altered, and blood flow resistance is rapidly raised. Common problems are raised blood pressure, heart arrest, heart failure, heart attacks, stroke and failure of other organs. Therefore, activities and environmental factors can affect the immune system through changing the condition for organ failure.

On the basis of a large number of post-1980 studies, we found that the human immune system is an "emotional creature" that is run and controlled by many influencing factors: emotional state [50-53, 81, 83-84], activities [54-66, 90], toxic substances [79-80, 101. 103], food and nutrition [93, 99-100], and environmental factors [89]. In addition, the human's ability to survive also depends on the current functional capabilities of the vascular system and other vital organs such as liver, kidneys and lungs.

\section{B. Immediate and Permanent Impacts of Life Factors on Immune System}

We assume that the body's ability to ward off infectious agents depends on the immune system's current functional capacities against the attacks of disease agents; the body's ability to withstand the impacts of the infection-induced inflammation depends on the organ's current functional capacity and the 
immune system's current functional capacities; the body's ability to maintain health depends on the garbage removal capacities integrated over time; and the ability to fix damaged tissue depends on repairing functional capacities integrated over time. Over those observations, more details can be added in future. To achieve the best outcome, it is necessary to study immune system's potential functional capacities and the current functional capabilities. It is critically important to understand how life factors affect the immune system's current functional capacities.

Life factors mean anything that could affect the tissue's ability to fix fault, control infection, repair tissue damages, etc. A large number of life factors can instantly depress the immune functional capacity. Permanent impacts of life factors are realized by altering cell genetics, tissue structure, and presumably the memory of the CNS. Current impacts of life factors are realized by present's compounds' interference with biological and cellular processes used by immune responses and temporary and reversible changes in cell and tissue structure. The immune system's the current capacities change in consistent with environmental factors, personal daily activities, general health, overall nutrition, and the profile of toxic profiles in the blood stream in each 24-hour period. Just a few important factors such as exposure to temperature, emotional distress, changes in nutritional profile, and all toxic substances (particularly those that can interfere protein binding), etc. can have huge impacts on the immune system's current capability. We will describe several examples below:

\section{The effects of exposure to low temperature on the immune system}

In our prior study [118], we established that exposure to cold air can reduce local blood flow rate to only a tiny fraction (as little as 5\%). This can instantly disable the mobility of all immune cells which are required to perform all vital functions such as cleaning virus-containing particles, removing dead infected cells, dead immune cells, and metabolic wastes, and repairing damages caused by infection. In addition, the immune depression can take place in a short time and may slowly recover upon warming up as predicted in FIG. 2. Temperature's role on COVID-19 is implied in studies involving influenza [119120]. In consistent with our finding, temperature was found to be the numbertwo factor affecting COVID-19 incidence rate (next to age) [121]. Based on the disease incidence patterns and death rate patterns, we could find that temperature is the most important factors for fighting the pandemic.

\section{The effects of prolonged intensive exercise on the Immune System}


Exercise's controversy was well known in medicine [122]. Moderateintensity physical exercises stimulate cellular immunity, while prolonged or highintensity exercises without appropriate rest can cause decreased cellular immunity and increased propensity for infectious diseases [123-124]. In most studies, researchers did not address exercise as dynamic activity involving massive system parameters. From 1980 to 1989, papers were published with evidence that heavy exertion was associated with transient immune dysfunction, elevated inflammatory biomarkers, and increased risk of upper respiratory tract infections. Those findings are expected if we know how exercise might affect the immune system dynamically.

Increasing attention is being directed to the enhanced immune surveillance of distinct immune cell sub-types during exercise time of less than 60 min that have potential prevention and therapeutic value [135-146]. In addition, it was found that moderate exercise can reduce risk of lung infection risk by $40-50 \%$ while heavy exertion can raise the lung infection risk by 2-6 folds, implying the intensive exercise can severely impair the current immune functional capacities.

We found that this is a unique problem to the lung infection because the lungs are routinely exposed to pathogens such as influenza virus. For other diseases and health problems, this may not be true because exposure to pathogens attacking other organs is at much lower probability; and thus other benefits such as raising anti-tumor immunity may outweigh the increased risk caused by extended or intensive exercise. For this reason, if one does exercise longer than 60 minutes or must do intensive exercise, he or she should understand the vulnerability time window for getting lung infection. Before the person recovers from fatigue, she or he should avoid exposure to all respiratory track disease agents.

Long-term effects. Recently discovered evidence supports that view that immunity can be remodeled during the aging process as a result of interactions with the environment and lifestyle and is instrumental in shaping immune status in later life [147-149]. Immune system interactions with pathogens, the host microbiome, nutritional and exercise influences, mental stress, and many other extrinsic factors are considered as crucial modulators of the immunosenescence process. Habitual exercise is capable of regulating the immune system and delaying the onset of immunosenescence. It enhances vaccination responses, lowers numbers of exhausted/senescent T cells, increases T-cell proliferative capacity, lowers circulatory levels of inflammatory cytokines (i.e., decreased "inflammaging"), increases neutrophil phagocytic activity, lowers inflammatory response to bacterial challenge, increases NK cell cytotoxic activity, and 
increases leukocyte telomere lengths [149-151]. All of those effects can be explained by improved immune cell mobility, reduced amounts of toxic substances and improved local nutritional availability, which are achieved from the exercise.

While exercise is the most powerful way to maintain good immune system, extended and excessive exercise can cause accumulation of toxic metabolic products, repletion of glucose level in blood and thus suppress immune function in a brief period of time. This is a time window, in which the person would be more vulnerable to disease agents attack. The impacts can be severe, depending on a large number of factors.

\section{The effects of severe emotional stress on the immune system}

While chronic stress can slowly alter immune capacity on nearly permanent basis, severe emotional stress can cause immediate immune suppression. This effect cannot be determined by running a clinical trial because its impact is short-lived. However, during the time of immune suppression, the body loses considerable immune capacity. Thus, its ability to fight against infection, remove garbage, and repair damaged tissues is diminished. If emotional stress is inflicted regularly or in conjunction of other immune suppression factors, its impact on the immune system as well as the long-term health cannot be ignored. Just having anxious thoughts can weaken the immune response in as little as 30 minutes. Severe stress can affect immune system immediately.

The fight or flight reaction is associated with activation of the sympathetic nervous system. The chain reaction brought about by this response can result in (1) increased heart rate and dilated blood vessel, (2) increased respiration rate and dilation of bronchi, (3) increased conversion rate from glycogen to glucose, (4) dilation of blood vessels serving muscles, (5) constriction of blood vessels serving digestion, and (6) restricting blood flow in non-essential parts of the body such as the periphery [154]. The response results in the secretion of catecholamines, especially norepinephrine and epinephrine [155]. The hormones estrogen, testosterone, and cortisol, as well as the neurotransmitters dopamine and serotonin, also affect how organisms react to stress [156]. Osteocalcin might also play part of roles [156].

Due to the involvement of a large number of stressful hormones, it is impossible to predict how an acute stress affects the immune system based on any single stress hormone. However, two facts are not disputed: In human neutrophils, adrenaline and noradrenaline inhibit migration, CD11b/CD18 
expression, and oxidative metabolism, and norepinephrine can also make blood vessels become narrower, increasing blood pressure. This implies that stress hormones do have inherently negative effects. That does not mean that stress response must be bad as a whole. Based on more recent studies involving animals, flight and fight response can actually boost immune. This finding can be justified from the evolutionary point of view, particularly in light of frequent use in wildlife. Then, how flight and fight response affects the immune system depends on a large number of surrounding factors and the final balance among multiple biological processes. By accepting balance-based method, we can easily identify three situations that are damaging the immune system.

\section{(1) Long lasting chronic stress}

When stress is lasting and enduring, the elevated high stress hormones can suppress the immune system [81-84]. We predict that the effects may be durable because altered biological process attributes of biological pathways networks cannot be easily restored. A partial correction can be achieved by reducing the current concentrations of the excessive stress hormones. However, structural change relevant to the immune system caused by abnormal immune responses cannot be undone. For this reason, we could consider them having both permanent effects and current effects. In the modern society, human lives are filled with anxieties, worries, uncertainty and hassles. Most of them are created to advance perceived social benefits. A vast number of problems are created by societies, primarily due to ignorance in the past. The highest enduring stresses are created by overwhelming practices related to academic competition, gamecompetition, business competition, employee promotion competition, certain commercial services, professional licensing and examination, abusive use of examinations, process-based litigation practices, family conflicts, social conflicts, racial conflicts, political conflicts, wealth disparity, etc. Additional practices include robot rating practices, robot performance review, robot customer services, robot messaging services, robot news services, etc. Some problems are noted in a study:

"Stress-related disease emerges, predominantly, out of the fact that we so often activate physiological system that has evolved for responding to acute physical emergencies, but we turn it on for months on end, worrying about mortgages, relationships, and promotions. (p. 7)" [81]. The abusive use of the defense system has both current adverse impacts and permanent impacts.

\section{(2) Extreme emotional distress and shock}


Emotional distress can have severe impacts on the current immune functions and permanent immune functions. A case report several cases [158], where five patients, respectively at the ages of $46,71,85,82$ and 86 , died shortly after they were involved in argument or were robbed, often with damages in the left ventricular free wall. While the study focused on heart function as cause of death, for the reason that will be obvious, the real death can be attributed to the compromised immune functions. Indeed, myocardial infarction or any other form of cause of death is only a final manifestation of the failed immune system. It is known that emotional distress can have permanent impacts on the immune system. Its impacts can be seen even after two decades after the exposure [159]: PTSD-positive veterans are more likely to have elevated leukocyte and CD4 and CD8 T-cell counts. Those with anxiety disorders have elevated counts of lymphocyte and T-cell counts. They also have more highly sensitized T-cell lymphocytes.

\section{(3) Excessive worries without physical violence}

It is well known that emotional stress can cause severe current impacts. A dose-response association exists between psychological distress and major causes of mortality across the full range of distress [160]. The impacts of excessive worries can be best explained by a related phenomenon, Voodoo spell [160A]. One exemplar case is that a person died one day before his negative cancer diagnosis report was issued. Before his death, the person had suspected that he had cancer. This kind of cases is not rare, but few were subject of research and reported in literature.

In this class of cases, the person is not a victim of any violence. Evidence of the possibility of a fatal outcome from profound emotional stress was reported by Mira in recounting his experiences as a psychiatrist in the Spanish War of 193639 [160A]. The patients suffer what he called "malignant anxiety," with signs of anguish and perplexity with rapid pulse (more than 120 beats per minute) and a very rapid respiration (about three times the normal resting rate). These conditions indicated a perturbed state deeply involving the sympathico-adrenal complex. Those conditions are often accompanied by physical exhaustion attributable to lack of food, fatigue, sleeplessness, etc. In fatal cases, death occurred in three or four days [160A]. While the cause of death may be attributed to "natural" cause in medicine, the root cause is a disturbed immune system that it is unable to maintain the working order of the body.

We noted that high ages among those reported cases imply that their deaths are related to their organ's reserve functions. Their vascular systems lose a considerable part of functional reserve, and perturbation in the immune system 
caused by emotional stress can more likely satisfy the condition of heart failure. In contrast, young persons more likely survive from severe emotional stress because they have very large heart functional reserve.

Emotional role on infection disease was revealed in a study involving Enterovirus 71 [160B]. The plasma levels of Norepinephrine and Epinephrine elevated in Enterovirus 71-infected patients with autonomic nervous system dysregulation and pulmonary edema. Both Norepinephrine and Epinephrine hormones enhanced the percentages of infected cells and virus titers in the viral infection in vitro. They may play a role in the pathogenesis of the virus in the patients.

\section{The effects of trauma, accidents, and wounds on the immune system}

Trauma and haemorrhagic shock induce numerous changes within this system which is ultimately deleterious and contribute to the high incidence of organ dysfunction and infectious complications. A trauma can cause magnitude of changes induced by physical injures and haemorrhage. Regional hypoxia and depletion of energy stores occur due to diminished micro-circulatory blood flow and altered cellular signaling, and result in the release of pro-inflammatory cytokines and prostanoids which mediate further suppression of immune function. It disrupts the normal acquired immune function, depresses cell mediated and humoral immunity, and may induce tissue damage in the lungs, heart, liver, and gut, etc. [161].

\section{The effects of toxic substances at toxic levels in plasma}

The effects of current concentrations of toxic substances on the immune current function capacities have not been studied. Each day, a person is exposed to a large number of substances, for most of which, no study has been done to understand their immediate impacts on the immune functional capacity. Most heavy metals may have both permanent impacts and immediate impacts. If one ingests $\mathrm{Hg}$, the high ion concentration may directly interfere with biological reactions of immune responses. While this effect is proportional to ionic concentration, it also causes damages to all cells. By its accumulative effects, $\mathrm{Hg}$ also causes systematical damages to cells, cell apparatuses, blood vessels, etc. with long-term effects. The permanent alternations in cells and tissue passed down from cells to cells by all known or unknown methods of preserving nongenetic changes. While we can provide several examples, one must think that a huge number of substances may have immediate impacts even though they have not been studied. It is also possible that some substances may have immediate adverse impacts, but may alter tissue structure with permanent effects. In this 
situation, it is important to avoid exposure to other disease agents at the time of immune suppression.

The common signs of this class of problems include indigestion, vomiting, diarrhea, stomach pain, abdomen pain, and other noticeable discomforts that are clearly caused by foods, drinks or things ingested. The symptoms normally resolve within thee days, but most individuals may recover as short as several hours to less than one day. The noticeable discomfort implies acute inflammation, relapsed chronic inflammation, or disturbed immune function. One common change is an increased number of immune cells count, which is predicted to raise blood pressure by hindering local blood flow. While the biggest impact is the immediate impact, each instance may have a permanent effect.

Absorption speed may be measured by absorption half life. The large value of half life implies a slowness of the substance in entering into blood circulation. Elimination half life tells how fast the substance is eliminated and predicts how long the immediate impacts can last on the body. One biggest group of toxic substances is heavy metals; and their elimination half lives are shown below [189].

$\begin{array}{ll}\text { Polonium in the body: } & 30 \text { to } 50 \text { days. } \\ \text { Caesium in the body: } & 1-4 \text { months. } \\ \text { Mercury in the body: } & \sim 65 \text { days. } \\ \text { Lead in the blood: } & 28-36 \text { days. } \\ \text { Lead in bone: } & \sim 10 \text { years. } \\ \text { Cadmium in bone } & \sim 30 \text { years. } \\ \text { Plutonium in bone } & \sim 100 \text { years. } \\ \text { Plutonium in the liver } & \sim 40 \text { years. }\end{array}$

For heavy metals (like Lead) with long half lives, it would take very long times to eliminate them after they have entered bone. Thus, removing them from the bone cannot be achieved, and a workable strategy is to lower their plasma concentrations by creating a concentration gradient. By avoiding lead intake and promoting lead elimination, one could reduce lead from the plasma. This would have an immediate benefit. If the body is maintained in this off-balanced state, the lead concentration in the bone will be slowly reduced.

\section{Effects of toxic substances without noticeable symptoms}

Due to the complexity of personal diets and the diversity of eatable food and drink supply sources, we assume that subtle injuries by toxic substances are common among all people. If an offending substance does not cause any localized damage or acute adverse reaction, temporary depletion of an organ's 
functions will not cause any sign of complaint. Moreover, most toxic substances do not cause acute signs of poisoning. Based on all known risks and other potential risks in food production lines and distribution practices, there must be situations, where offending substances do not cause localized signs. Their exposures may be of a limited nature so that they could not depress any organ's function to reach a level of feeling discomfort. Yet, they can depress the immune function capacity temporarily.

A person may be exposed to a very high amount of heavy metal such as lead from using a pan made of scraped metal materials containing the heavy metal. The food cooked may contain lead which could be tens to thousands of times of legal permissible limit. While severer damage may be realized by longterm effects, lead ions may be enough to depress the immune functions by its a current impact. While many known toxic substances are the subjects of concern, there are a large number of chemicals that have not been studied. The common sources of exposure may include utensils, plastic containers, kitchen materials, processing aids, food colorants, food flavors, food additives, pesticides, herbicides, etc. Many of heavy metals ( $\mathrm{Ni}, \mathrm{Cr}, \mathrm{Cd}, \mathrm{Pb}$ and $\mathrm{Cu}$ ) have been found in old cookware; many toxic substances from plastic materials have been known; and a large number of them are yet to be found. While existing studies have focused on their long-term cumulative effects on health, many of them must suppress the immune function by their immediate effects. While the brief effect of an isolated substance may be of little concern, its importance must be considered in light of a massive number of other immune suppressive substances.

\section{Acute allergic reactions}

Allergies may be caused by foods, drinks, smell, dusts in breathed air, or anything transferred by physical contact. It may be caused by medicines, injections, etc. A person becomes allergic when his body develops antigens against the substance. Allergy is the result of the immune system's response to a substance. Common signs of allergies may be coughing, runny nose, skim rush, etc. Other signs include itching, red rash and hives, feeling warm, dizziness, headache, nausea, vomiting or diarrhea, anxiety, chest tightness, swelling of the throat and tongue, tightness in throat, trouble breathing or shortness of breath, abnormal heart rate (too fast or too slow), pain or stomach cramps, loss of consciousness, and shock. The most severe sign is a life-threatening reaction known as anaphylactic shock, which may occur within minutes or sometimes up to an hour or more after exposure to allergens. There may be a sudden drop in blood pressure. 
Anaphylactic shock can be explained by immune response. When an antigen binds to the B-cell surface, it stimulates the B cell to divide and mature into a group of identical cells called a clone. The mature B cells, called plasma cells, secrete a large amount of antibodies into the bloodstream and lymphatic system. To generate a severe symptom, a large amount of antigens is present to cause massive B cell production. The excessively large population of B cells as well the large amount of antibody-antigen aggregates can dramatically increase the blood flow resistance, thereby creating the condition that the heart is unable to maintain the normal blood circulation. During the allergic response, it is predicted that the immune system generally has a diminished capacity to fight other disease agents because the agents burden the heart.

\section{Immune suppression caused by food poisoning}

Food poisoning is a common problem that is predicted to have instantaneous impacts on the immune system. Food poisoning is defined as an illness caused by the consumption of food or water contaminated with bacteria and/or their toxins, or with parasites, viruses, or chemicals. The symptoms vary in degree, but common signs include abdominal pain, vomiting, diarrhea, and headache; more serious cases can result in life-threatening neurologic, hepatic and renal syndromes.

Common pathogens are norovirus, salmonella, C perfringens, campylobacter species, staphylococcus aureus, toxoplasma gondii, E coli, T gondii, and listeria monocytogenes [162-163]. Many toxins include lathyrus sativus, mushrooms, argemone mexicana, poisonous fish like shell fish, scombroid fish etc. and mussel [162]. A large number of toxic substances may come from foods [103]. In reality, if "subtle" food poisoning caused by chemicals, the person most probably lacks detectable symptoms; and thus chemicalsinduced mild food poisoning is not widely reported.

In one study done by CDC, the researchers estimate that food borne diseases cause approximately 76 million illnesses, 325,000 hospitalizations, and 5,000 deaths in the United States each year. Known pathogens account for an estimated 14 million illnesses, 60,000 hospitalizations, and 1,800 deaths. Three pathogens, Salmonella, Listeria, and Toxoplasma, are responsible for 1,500 deaths each year, more than $75 \%$ of those caused by known pathogens, while unknown agents account for the remaining 62 million illnesses, 265,000 hospitalizations, and 3,200 deaths [163]. The data reflects the prevalence of food poisoning. Undetectable food poisoning is predicted to be very common. 
If food poisoning is caused by chemicals, clinical signs indicate that the person has eaten too much of food so that at least one compound has reached toxicity level to cause inflammation. It is possible that multiple chemicals or even a large number of them might strike the immune systems by their immediate effects. Which compound reaches a toxicity level could depend on individual foods and their relative content. We believe that, in most cases, mild food poisoning cannot be determined, and assume that toxicity of food-borne compounds are most probably responsible for the cases with mild or no symptoms.

The incubation time can be anywhere from 1-16 hours while some may take more time to develop symptoms. The rate parameters implies that poisoning processes have big impacts on the immune system in the short-time window.

\section{Immune suppression caused by environmental factors}

Immune system is sensitive to temperature [87, 89], humidity [120, 164], air oxygen pressure [162, 165], mechanical vibrations [166-167] and other physical properties. Due to lack of commercial value, those factors have not been used in treating diseases. Oxygen may have different effects. In trauma cases, a very low oxygen level caused by hypoxia is found to disrupt the immune function leading to poor outcome. Hypoxia may play a role in causing immune-mediated renal damage in transplantation setting. A lower oxygen level is found to stimulate immune function and thus results in kidney injury. Those findings imply that low oxygen levels can cause damages to other tissues. However, it is also known that excessive high levels of oxygen supply could cause oxygen poisoning and thus hurt lungs [169]. This poisoning risk may be as high as 1 in 200 at higher pressures (2.8 to 3.0 times of normal atmospheric pressure) and as low as 1 in 10,000 for treatment at 2 atmosphere absolute air or less [169]. Those findings suggest that degraded oxygen supply below the air oxygen level may disturb the normal immune functions, but oxygen poisoning can happen only artificial ventilators are used.

Over production of B cells can be a problem for causing tissue injury and heart damages, and thus suppressing B cell production speed is desirable. A rough calculation shows that the vibration in the frequency range of $22-50 \mathrm{kHz}$ is effective for controlling the mitosis of human cells [166]. There is evidence that cell division could be disrupted by sea waves [167]. Exercise can cause mechanical agitation, which could prevent excessive B cell production and also may facilitate existing $B$ cells transport between the diseased tissue and circulating blood [168]. Based on how immune cell migrate, we predict that mechanical vibrations facilitate immune cell migrate out of lung tissues [168]. 
Most people might have the experience that eating a large amount of hot food and then immediately eat a large volume of ice-cold drink can cause discomfort. When the stomach is filled with hot food, its tissue structure is expanded. Then, the sudden contact with ice-cold drink will cause the body to constrict rapidly. This change can disrupt blood circulation and immune cell transportation balance from a fast migration mode to a near stop. It must hurt the person badly. For a brief moment, the immune functional capacity is very low. If the food or drink also contains influenza or other viruses, the viruses can exploit the weaken immune system in launching its attack to the digestive track. The second problem is the physical stress caused by overeaten food on the walls of the digestive track. In addition, the toxicity of substances could be caused by eating too much food containing compounds (too much salts, too much species, etc.), but physical force generated by excessive food volume may be responsible for acute inflammation which burdens the immune system locally or globally.

Another large class of properties that affects the immune system is physical properties, which may be anything that affects tissue structure by a nonchemical mechanism. They include physical barriers, electronic charges, nonionic attracting force, particle-particle interactions (viscosity), volume occupancy, etc. The presence of a large number of inert particles can affect the immune cell mobility and the functional capability.

\section{Immune suppression caused by other infections}

Since the immune system is a shared system, the presence of multiple antigens and foreign matters is predicted to generate an excessive number of immune cells. If a person has multiple infections, each infection results in a large number of B cell clones at lymph nodes respectively near their diseased tissues. In an attempt to resolve infections, all immune responses must compete for the resources of the immune system, and are predicted to affect the body's ability to fight against a particular disease agent, unless the arm of the immune system against one infection can work against the other infectious agent, or promoted immune reaction work on both infectious agents. Production of an excessively large number of $\mathrm{B}$ cells and $\mathrm{T}$ cells may disturb the required balance of the immune system.

The ability to accommodate immune cells numbers (in terms of total cell volume/blood volume) is limited. Based on our simulations for lung damages for COVID-19, if cell number increases, the flow resistance can rapidly rise in a manner like a doubly exponential curse. When more and more immune cells are retained in the diseased tissue and other tissues dynamically, the blood flow resistance can reach very high value and thus results in heart failure, stroke or 
thrombosis or organ failure. If a person has multiple diseases, it could have poor ability to fight each of them. All infections and inflammations can jointly burden the vascular system to reach the end point of killing the patient.

Based on laboratory data, some B cells always find their ways into the main blood. The elevated immune cells cause blood viscosity to rise. In addition, hormones released as a result of pain and discomfort, sleep deprivation and related fatigue also weaken the immune function. Expected side-effect of drugs, which are used to treat an infection, may also weaken immune system's current functional capacity. While the effects of the second infection on a primary infection cannot be detected in clinical trials [1-2], they could be proved by theoretical approach [187]. Influenza infection is found to enhance the production of the anti-inflammatory cytokine interleukin (IL) 10 (IL-10), thereby suppressing the overall immune response and increasing susceptibility to secondary infections [219].

\section{Malnutrition and temporary nutritional imbalance}

Malnutrition is a well studied factor for more vulnerable viral infection [170-171]. It is possible that some persons may lack vitamins (especially A, C, and E), zinc, and other essential nutrients for functional immune system. This can be a real problem for travelers who temporally lack fruits and vegetables during travel.

The impacts of malnutrition can be severe. We read about a case from a popular media that a person died from eating packaged noodles for an extensive long period of time. The person daily ate packaged noodles that can be served by adding boiling water. After living this monotonic lifestyle for months, this person suddenly died in his research laboratory. The most rational explanation of cause is that he has been in malnutrition. From his diet, we infer that he could not get enough vitamins, minerals, and all essential micro nutrients. The malnutritioninduced poor immune system is unable to maintain tissues and organs health, and the slowly degradation in tissues result in loss of organ's functional capacity. In addition, malnutrition also has current impacts on the immune functions by directly impairing biological processes involved in immune responses. When essential nutrients such as vitamins (A, C, E, D), minerals (zinc, calcium, magnesium, etc), and other required micro-nutrients are lacking, all biological pathways could not run as in healthy persons. In addition, the noodles contain production-line contaminants, food additives, colorants, and artificial flavors, etc. it is only a matter of time for a life stress to cause the vascular system to fail. 
Malnutrition is predicted to be much severer than what is revealed in current literature. It is possible that some people may lack some nutrients even though other nutrients are in surplus. Malnutrition can have permanent effects by altering the cell and tissue structure. Lack of essential nutrients as well as the presence of toxic substances may accelerate aging, toxic cellular damages, etc, slowly reduce the potential functional capacity of the immune system, and reduce its current functional capacity.

\section{Effects of sleep deprivation and oversleep on the immune system}

Sleep affects the immune system by very complex mechanisms [172-174]. Sleep provides essential support to the immune system. Getting sufficient hours of high-quality sleep enables a well-balanced immune defense that features strong innate and adaptive immunity, and less severe allergic reactions. Serious sleeping deprivation and accompanied circadian rhythm disruption can interfere with the normal functioning of the immune system. It is hard to predict the effects of sleep on the immune function by merely looking at biomarkers. Getting enough high-quality sleep facilitates the delicate balance between different arms of the immune function.

Sleep can help the brain consolidate memory, and strengthen immune memory. The interaction of immune system components during sleep reinforces the immune system's ability to remember how to react to different antigens. During sleep, breathing and muscle activity slow down, freeing up energy for the immune system to perform these critical tasks. During sleep, there is an increased production of cytokines associated with inflammation. This component has both immediate impacts and long-term impacts.

Longer sleep habits are also bad [175] because they are associated with cognitive impairment, depression, increased inflammation, increased pain, impaired fertility, higher risk of obesity, higher risk of diabetes, higher risk of heart disease, higher risk of stroke, and higher all-cause mortality [175]. Oversleep may result in calories imbalance, which in turn results in excessive deposit of fats in tissue and longer inactivity time. It ruins all channels for immune cell migration. What constitutes oversleep depends on personal health, age, activities, overall diets, etc.

\section{Immune suppression by fatigue and exhaustion}

Many studies and general observations indicate that the effect of fatigue on immune parameters depends on the level of fatigue, and that the amounts of subsets peripheral blood T cells are useful for evaluating levels of fatigue [176]. A person's immune system may be too exhausted to fight [177]. While lack of 
available energy could be a factor, the accumulation of metabolic by-products is most probably the main reason since the immune system performs garbage removal [105]. The adverse impacts of moderate fatigues are temporary as the immune function can be restored with enough sleep or break. However, regular and routine excessive fatigues may have accumulated and more durable impacts on the immune system.

\section{Effects of alcohol, recreational drugs, smoking, chemicals etc. on the immune system}

It is well known that a large number of things including alcohol, smoking and recreational drugs can suppress the immune function.

The National Institute on Alcohol Abuse and Alcoholism (NIAAA) warns that a single episode of drinking can suppress the immune system for up to 24 hours [178]. Additional studies also show that drinking, even once, can suppress the immune system afterward for a short time. In addition, drinking too much blunts the body's repair function and increase risks of getting illnesses like liver disease, pneumonia, tuberculosis, and certain cancers. While the long-term effects are realized through time, the short-term effect can be realized rapidly. Since their impacts cannot be detected without exposure to second disease agents so that its true role of alcohol is grossly underestimated. This will become important in light of other immune suppressive factors.

Alcohol use over prolonged periods of time will cause long-term immune system problems [179]. While alcohol's actual effects on the immune system are complex at a chemical and cellular level, chronic alcohol use has been shown to affect every area of the immune system [179]. It significantly increases the risk of developing infections, even causing infections that a healthy person would not normally be at risk. In addition to suppressing every area of the immune system, these long-term changes may also cause inflammation. The role of smoking on the immune system is so well known and there is no need to repeat here.

Recreational drugs also affect the immune system [180-182]. Some well known recreation drugs are nicotine (Tobacco), Bath Salts, Opioids, Marijuana, Cocaine, Ecstasy, Flakka, Heroin, Krokodil, LSD, Methamphetamines (crystal meth), Psilocybin and Peyote Mushrooms, Salvia, Spice, MDMA, etc. The drugs affect all cells (B cells, $\mathrm{T}$ help cells, immune cells lines, and macrophages). Most of drugs deliver immediate effects while they can also deliver long-term damages.

Many industrial materials and industrial chemicals can impair the immune system. A search conducted at the Toxicant and Disease Database [104] by using 
a search key "Immune suppression" returns the following immune suppressants, grouped by strength of evidence:

Strong Evidence: benzene, dioxins/TCDD, ionizing radiation, tobacco smoke (active smoking), tobacco smoke (secondhand), UV radiation

Good Evidence: aldicarb, asbestos, benzo(a)pyrene, carbamates, chlordane, chlorpyrifos, dichlorvos, lead, mercury, methyl isocyanate, nickel, nitrogen dioxide, organochlorine, pesticides, organophosphates, PAHs, PBBs, PCBs (polychlorinated biphenyls), PCDDs, PCDFs, pentachlorophenol (PCP), pesticides, phosgene.

Limited Evidence: 1,1,1-trichloroethane, 2,4-D, arsenic, atrazine, beryllium, cadmium, carbon tetrachloride, chromium, copper, DES, diesel exhaust, estrogens/DES, ethylene glycol ethers, formaldehyde, hexachlorobenzene, nitrogen dioxide, nitrosamines, organotins, ozone, pesticides, phenoxyacetic herbicides, platinum, silica, solvents, sulfur dioxide, tetrachloroethylene (PCE), titanium dioxide, toluene, tributyl tin oxide, trichloroethylene (TCE), triphenyltin, urethane, vinyl chloride.

Many of the above-listed substances can be found in our environment, water, soil and air. This list does not include prescription drugs. Among a massive number of industrial chemicals, most (perhaps $>97 \%$ ) have not been studied. Even if a substance has been studied, the true role on human immune system cannot be determined accurately due to use of flawed population-based method, lack of trial duration, and failure to consider human organ's redundant functions [113-115, 187]. When the mean of a treatment group is same as the mean of a control group, a negative conclusion does not mean the chemical in fact has no effect on all people.

\section{Immune suppression by medications}

Many drugs are known to have immune suppression effects [183-185]. They include drugs to treat allergies, arthritis, lupus, IBS, and organ transplant.

Drugs suppress immune function by one of several mechanisms of action. Classical cytotoxic immuno-suppressants act by inhibiting DNA synthesis. Others may act through the activation of $T$ Cells or by inhibiting the activation of help cells. Immunosuppression has been brought about in the past primarily to prevent rejection of transplanted organs, and counter the effects of interleukins and other cytokines. A search on Drug Bank will show 288 drugs [186]. Corticosteroids are one example, as are TNF inhibitors for inflammation and 
chemotherapy for cancer. Most of the drugs have immediate effects while many of them may also work through slowly delivered long-term effects.

We assume that immune suppressive drugs are determined by research model for strong effects. Most of the drugs that affect the immune system by influencing other organs such as heart, kidneys are not included. Based on weak effects that might work through indirect but clearly anticipated mechanisms, most medicines must have weak effects. Their effects could not be detected due to the massive organ surplus functions. If we consider weak effects, any drugs that have known impacts on CNS, heart, DNA, kidneys, etc. are predicted to negatively affect the immune system. However, their current effects are so weak that it may be impossible to detect their effects by using current research methods.

The common immune suppressive drugs include corticosteroids such as prednisone (Deltasone, Orasone), budesonide (Entocort EC), prednisolone (Millipred); Janus kinase inhibitors such as tofacitinib (Xeljanz); Calcineurin inhibitors: cyclosporine (Neoral, Sandimmune, SangCya), tacrolimus (Astagraf XL, Envarsus XR, Prograf); mTOR inhibitors: sirolimus (Rapamune), everolimus (Afinitor, Zortress); IMDH inhibitors: azathioprine (Azasan, Imuran), leflunomide (Arava), and mycophenolate (CellCept, Myfortic); Biologics: abatacept (Orencia), adalimumab (Humira), anakinra (Kineret), certolizumab (Cimzia), etanercept (Enbrel), golimumab (Simponi), infliximab (Remicade), ixekizumab (Taltz), natalizumab (Tysabri), rituximab (Rituxan), secukinumab (Cosentyx), tocilizumab (Actemra), ustekinumab (Stelara), vedolizumab (Entyvio), Monoclonal antibodies, basiliximab (Simulect), daclizumab (Zinbryta).

The current effects of drugs are reflected in their half lives. Half life of a drug is the time required for the drug to reduce half in the plasma level.

The elimination half life of prednisone is around 3-4 hours [188]. This is the time it takes for the body to reduce its plasma level by half. It usually takes around 5.5 times of half-life for a drug to be completely eliminated from the body. The impact of this drug is gone in about one day. The half lives of other drugs are shown in the following table (cited from Wikipedia) [189].

Table 1. The Biological Half Lives of Some Exemplar Drugs

\begin{tabular}{|l|l|}
\hline Substance & Biological half-life \\
\hline Adenosine & Less than 10 seconds (estimate) \\
\hline Norepinephr & 2 minutes \\
\hline
\end{tabular}




\begin{tabular}{|c|c|}
\hline ine & \\
\hline Oxaliplatin & 14 minutes \\
\hline Zaleplon & 1 hour \\
\hline Morphine & 1.5-4.5 hours \\
\hline Flurazepam & $\begin{array}{l}2.3 \text { hours } \\
\text { Active metabolite (N-desalkylflurazepam): 47- } \\
100 \text { hours }\end{array}$ \\
\hline $\begin{array}{l}\text { Methotrexat } \\
\text { e }\end{array}$ & $\begin{array}{l}\text { 3-10 hours (lower doses), } \\
\text { 8-15 hours (higher doses) }\end{array}$ \\
\hline Methadone & 15-72 hours in rare cases up to 8 days \\
\hline Diazepam & $\begin{array}{l}\text { 20-50 hoursActive metabolite (nordazepam): 30- } \\
200 \text { hours }\end{array}$ \\
\hline Phenytoin & 20-60 hours \\
\hline $\begin{array}{l}\text { Buprenorphi } \\
\text { ne }\end{array}$ & 28-35 hours \\
\hline Clonazepam & 30-40 hours \\
\hline Donepezil & 3 days (70 hours) \\
\hline Fluoxetine & $\begin{array}{l}\text { 4-6 days (under continuous administration) } \\
\text { Active lipophilic metabolite (norfluoxetine): 4-16 } \\
\text { days }\end{array}$ \\
\hline Amiodarone & 14-107 days \\
\hline Vandetanib & 19 days \\
\hline Dutasteride & 21-35 days (under continuous administration) \\
\hline Bedaquiline & 165 days \\
\hline
\end{tabular}

The data in Table 1 shows that most medicines have relatively short half lives. Such data conclusively support our point that most drugs have strong immediate impacts which can quickly disappear. However, damages, if any, may be accumulated by repeated use, routine use, or abusive use (e.g., at large doses 
with toxicity). Their permanent impacts on the immune system are realized by permanent damages to cells and tissues.

We also note that most cancer drugs have relatively short half lives (shown in Table 2 below):

Table 2. The Half Lives of Some Cancer Drugs

\begin{tabular}{|c|c|c|c|}
\hline $\begin{array}{l}\text { Cancer } \\
\text { type }\end{array}$ & $\begin{array}{l}\text { Short } \\
\text { Name }\end{array}$ & Drugs and Half Lives & Comments \\
\hline \multirow[t]{2}{*}{$\begin{array}{l}\text { Breast } \\
\text { cancer }\end{array}$} & $\mathrm{CMF}$ & $\begin{array}{l}\text { Cyclophosphamide: } 3-12 \text { hours } \\
\text { Methotrexate: } 3-10 \text { hs or } 8-15 \\
\text { hs } \\
\text { 5-Fluorouracil: } 16 \text { min } \\
\text { Vinorelbine: } 27.7-43.6 \text { hours }\end{array}$ & $\begin{array}{l}\text { Eliminated in 2-3 } \\
\text { days. }\end{array}$ \\
\hline & $\mathrm{AC}$ & $\begin{array}{l}\text { Doxorubicin: } 12 \mathrm{~m} / 3.3 \mathrm{~h} / 30 \\
\text { h/Mn: } 1-3 \mathrm{hs} \\
\text { Cyclophosphamide: } 3-12 \text { hours }\end{array}$ & $\begin{array}{l}\text { Eliminated in 2-3 } \\
\text { days. }\end{array}$ \\
\hline \multirow{3}{*}{$\begin{array}{l}\text { Hodgkin's } \\
\text { lymphoma }\end{array}$} & TAC & $\begin{array}{l}\text { Docetaxel: } 86 \text { hours } \\
\text { Doxorubicin: } 12 \mathrm{~m} / 3.3 \mathrm{~h} / 30 \\
\text { h/Mn: } 1-3 \mathrm{~h} \\
\text { Cyclophosphamide: } 3-12 \text { hours }\end{array}$ & $\begin{array}{l}\text { Docetaxel stays for } \\
\text { several days. }\end{array}$ \\
\hline & ABVD & $\begin{array}{l}\text { Doxorubicin: } 12 \mathrm{~m} / 3.3 \mathrm{~h} / 30 \mathrm{~h} / \mathrm{Mn} \text { : } \\
\text { 1-3 h } \\
\text { Bleomycin: } 2 \text { hours } \\
\text { Vinblastine: } 24.8 \text { hours } \\
\text { (terminal) } \\
\text { Dacarbazine: } 5 \text { hours }\end{array}$ & $\begin{array}{l}\text { Vinblastine stays for } \\
\text { several days. }\end{array}$ \\
\hline & MOPP & $\begin{array}{l}\text { Mustine: } \\
\text { Vincristine: 19-155 hs (mn: } 85 \\
\text { hs) } \\
\text { Procarbazine: } 10 \mathrm{~min}\end{array}$ & $\begin{array}{l}\text { Vincristine stays for } \\
\text { several days. }\end{array}$ \\
\hline
\end{tabular}




\begin{tabular}{|c|l|l|l|}
\hline $\begin{array}{c}\text { Non- } \\
\begin{array}{c}\text { Hodgkin's } \\
\text { lymphoma }\end{array}\end{array}$ & CHOP & $\begin{array}{l}\text { Prednisolone: 2-3 hours } \\
\text { Cyclophosphamide: 3-12 hours } \\
\text { h/Mn: 1-3 h } \\
\text { Vincristine: 19-155 hs (mn: 85 } \\
\text { hs) }\end{array}$ & Vincristine stays for \\
several days. \\
Prednisolone: 2-3 hours \\
$\begin{array}{c}\text { Germ cell } \\
\text { tumor }\end{array}$
\end{tabular}




\begin{tabular}{|c|l|l|l|}
\hline & & Vinorelbine: 27.7-43.6 hours & \\
\hline $\begin{array}{c}\text { Colorectal } \\
\text { cancer }\end{array}$ & FOLF & $\begin{array}{l}\text { 5-Fluorouracil: 16 min } \\
\text { Folinic acid: 6.2 hours } \\
\text { Oxaliplatin: 10-25 min }\end{array}$ & $\begin{array}{l}\text { Cancer drug rapidly } \\
\text { eliminated. }\end{array}$ \\
\hline
\end{tabular}

Cancer drugs with long half lives include Vinblastine (24.8 hours), Vinorelbine (27.7 to 43.6 hours), Vincristine: (19 to 155 hours; mean: 85 hours), Epirubicin (30-100 hours), and Docetaxel (86 hours).

Other drugs with short half lives include Chlormethine (1 min), Carboplatin (1.1-2 hours and 2.6-5.9 hours), and Paclitaxel (5.8 hours). Fentanyl (8-10 hr elimination half-life) was followed by sufentanil (6-9 hr), alfentanil ( $2 \mathrm{hr}$ ), and remifentanil [189a-189b]. Most of pain killers have the action duration about 3 to 6 hours [189c].

We found that a vast majority of medicines have short half lives. We believe it is necessary to use drugs with short lives. The common practice in clinics is to use different drugs to see which one would work for a particular patient. If a drug has an acute adverse reaction, a short half life would give the patient a better chance to eliminate the drug as quickly as possible. A long half life means it is more difficult to get rid of. This nature also means that most drugs are used with large doses with strong immediate impacts while the long-term effects are realized by large doses, repeated use and routine use, as in cancer treatments.

\section{Effects of other chronic diseases on the immune system}

All diseases cause local inflammation and various degrees of systemic inflammation which may be not detected by current research method. Stress hormones caused by worries and emotional pains negatively affect the immune system. Immune suppression may be caused by cumulative damages caused by treatment drugs, as in cancer cases [116-117]. As we will show, all diseases will burden the body in two vital functions: garbage removal and tissue repair; and all diseases jointly determine the final point of death: heart failure. Thus, if disease A cannot be effectively treated, treating disease B can have the same effect of extending the patient life. In addition, by treating minor diseases, one can actually boost the immune functional current capacities for fighting the challenging disease. For the same reason, proper management of personal life activities can have an effect of extending patient life. 


\section{A combination of various immune suppressive factors}

In reality, a series of events or exposures may take place in a sequence to cause severe immune suppression. For example, a person first does very intensive exercise to reach a fatigue level, then is exposed to hot temperature briefly, and followed by exposure to low temperature. Lack of glucose level in the blood, and high toxic actions of accumulated metabolic by-products can cause immune suppression. If this person is also exposed to influenza or COVID-19, the immune system may be too exhausted to fight. The current state of the immune system is diminished blood circulation, inability to remove metabolic byproducts, and lack of energy for restoring anti-viral functions. It would be the most vulnerable time for viral attacks. It is very possible that several to tens of weak factors with some super strong factors may hit a person at the same time and thus make the person vulnerable to attacks by all kinds of disease agents.

Each of such events or life activities may depress the immune system functional capacities temporarily, showing a big drop as in FIG. 2. The immune functional capacities then recover. The effects of emotional stress, temperature, and toxic reactions are shown in FIG. 2. For toxic substances, the curves shapes also depend on the absorption speeds of the substance. So, if a toxic substance is slowly absorbed, it may cause a delayed response. It is possible that a toxic substance is ingested in a first day, but its plasma concentration hit a peak the next day (or on a day when the person is not exposed to any immune suppressing factor). This makes it even more difficult to identify real cause of immune suppression.

\section{An Exemplar Pattern of Current Immune Functional Capacities}

We will show how humans have created a lifestyle, working environment, and culture to suppress the immune system routinely. In nature, the immune system is mainly used to fight against the danger that is perceived by animals with limited intelligence. The increase in human intelligence is one important factor because humans are able to appraise risks and dangers far more than what their ancestors could.

In a typical day in a summer, one person, John Doe, started up in the early morning, drives car to work. He might constantly struggle to beat red lights and stop signs, and in times, he might narrowly avoid accidents. He may strain every nerve and muscle to save five minutes.

After parking his car in a parking lot, he gets out of his car and walks through streets to go to his office. When he has generated enough sweating, he is exposed to cold temperature or cold air in his office. The sudden change in 
body temperature causes his CNS to signal the body to constrict blood vessels. Now, his starts having his anti-vial immunity shut down while he starts breathing in viruses discharged from other occupants and circulated by the ventilation system.

He then attends a meeting where he is criticized for lack of performance or failure to meet required sale quota. He may argue with his supervisor. Before he has a chance to restore temperature-suppressed immune system, he raises his stress hormones to further depress his immune function.

During work, he may feel boring, and think about mortgages, car loans, business concepts, best chances to win lotteries, competitors, with intermittent thoughts about things about himself, his family members, his friends, etc. High stress hormones are maintained.

If it is not an ordinary day, he might get a phone call from his family about an important event like a tree falling on his roof, his son being in a fight, his dog being sick, or something that requires his immediate attention and worries.

After several hours of intensive work, it is finally the lunch time. He rushes to a fast food shop to get something fast because he still has another meeting at $1 \mathrm{pm}$. If he is lucky, he may get a decent meal which helps him to restore suppressed immune system a little bit. By strike of bad luck, he might get a meal that results in allergic reaction, intolerance, poor nutrition, and in the worst cases, a food poisoning. To relieve the discomfort, he takes a pill from a sorted pain killers or from one of his co-workers. Even if he has no sign of diseases, a massive number of man-made chemicals are attacking his immune system with both undetectable immediate impacts and long-term impacts that cannot be detected.

It is finally the time to go home, he repeats the morning experience to beat traffic jam. If he is in a bad luck, he might hit someone or be hit by someone, and might get additional stress over what had gotten. In a worst case, he might be beaten up for causing a severe accident by a survival victim who could control his temper.

If he needs to buy groceries, he visits a grocery, he now suddenly change the temperature from $80^{\circ} \mathrm{F}$ to nearly $40^{\circ} \mathrm{F}$. Before his immune system has fully recovered, it was severely depressed again. The sudden change gives the viruses that he had breathed in from the office building a chance to thrive.

After exposure to pollutants from air and having ingested an unknown amount of contaminants, colorants, preserves, artificial hormones, pesticides, 
and herbicides, his body is in a really poor shape. He combines stress from being traffic, from the work place and his personal affairs, he is really tired. He may drink a cup of alcohol to relieve stress, and thus further suppresses his immune functional capacity. If he believes that a recreational drug could relieve the stress, he might use it. If he has a chronic disease, he might take one to ten prescription drugs regularly. The combined load of total toxic substances in his body may be enough to poison a snake.

If the man is really unfortunate, he might be pursued by policeman due to a mistaken identity. He is forced to get out of this car under the gun point, is handcuffed, and sent to a policy station. Upon further investigation, he is released for being an identity mistake. He earns an apology from the policy chief, but a severe impact on his immune system cannot be undone quickly as well as a deep scar in the memory by this emotional trauma. If he is indeed the right suspect, he would have to go through the booking process or being released.

If he finally gets home with all those unfortunate events, he might be blamed by his spouse or other family member for all of those problems. The expected limited recovery time is dramatically cut short by meaningless arguments on what he should have done.

The academic stress created by the vicious competition has ruined one to several generations of people except society has not realized the costs to life and economy. The authors have seen a large of number of instances that people at the ages from 40 to 60 suddenly die from no cause. This seems to be a pattern that was not seen half a century ago. Impacts from persistent high stress are permanently in their bodies and a massive number of toxic substances have been stocked in their organs, bones and tissues.

The vicious academic competition was formed after 1940, but has gained wide acceptance in the world, but societies have not understood the extremely adverse impacts on the young generations, and the final price tag that society must pay for their ruined health. It was predicted that the medical spending could reach nearly $\$ 6$ trillions in U.S., but the actual figure may be much higher based on more realistic projections.

If the about described events happen occasionally, there is no need to concern. However, this is a normal way of modern people's life. In realty, the real situations can be much worse. For example, young students are urged to achieve the top 10 percents in test scores. When everyone wants to reach the top ten percent, $90 \%$ of them must fail. So, they have to fight for success at a small probability that is predicted to be impossible. Under such an inhuman 
competition environment, the young people start working like robots from 6 am to 12 am, all day, every day, with endless classes, review sections, laboratories, research projects, and self-learning sections. They keep doing homework, taking mock tests, solving homework by volumes, etc, all for the purpose to achieve a top ranking that is impossible for most them, both theoretically and practically. While their test scores may or may not help them to achieve future success, their failed health is real and beyond dispute, they must deal with for their lifetimes and society must bear this huge burden.

For whatever reason, society is good at promoting things to injure public health and destroy our own chance to survive on the planet. For example, overwhelming businesses are run by robots. A story tells that a contractor worker, who is a good worker, was fired by a robot that is unable to understand real issues. Businesses are run by robots that simply lack intelligence to do right jobs. For most consumers, it is a real pain to deal with robots. Such robot systems waste people time, inflict pains, and create all kinds of mishaps for people. As reflected in the story, Fired by Robots, the employee just can never get a chance to have his issue evaluated. The story reveals that appeal is also heard by robots and the case is finally decided by robots. We found that this practice can have widespread impacts on public health.

For a healthy person, the ability to defend against a disease such as COVID-19 infection, cancer or heart disease can vary from nearly $100 \%$ to as little as $5 \%$ in each 24 hours period. It is possible several to tens of factors strike his immune system at the same time purely by strike of luck. Because each person's daily life experience is unique, the precise immune functional capacity profile in any three days period must be dramatically different from the profile for another three days. The profile of one person in any given time window is completely different from the profile for another person for the same time period. A hypothetical immune functional capacity profile is shown in FIG. 3 . That is why nearly all old people suffer at least one chronic disease and society can ever have enough resources to provide medical care for the population.

\section{A MODEL FOR EVALUATING IMMUNE FUNCTION CAPACITIES AND INFLUENCING FACTORS}

We will develop a model for evaluating the immune system and use six classes of health properties for identifying influencing life factors. 


\section{A. Immune System Defined by Six Classes of Properties}

All functions of the immune system depend on cell health in the tissue and the ability of immune cells to move into and out of the tissue. A good immune system depends on the tissue's blood-circulation features. Good mobility of immune cells is a critical requirement for the proper functions of all arms of immune functions and tissue repairing functions. Our prior researches have allowed us to find current functional capability of the immune system and propose the following six classes of health properties:

The micro vascular networks. Micro-circulation in tissue depends on capillary length, capillary density and capillary distribution in tissues. Those properties are important to all tissues particularly all vital organs such as heart, lungs, kidneys and brain.

Capillaries pore sizes. This property may be combined with the micro vascular networks for convenience, but it is the most important property.

The elasticity of tissues. Since the immune cells must migrate through the spaces between tissue cells, the loose packaging of the tissue cells is critically important to the proper function of the immune system. Tissue cells should be healthy and without structural damages. Cell damages caused by aging, heavy metals and pollutants will destroy the order of cells and thus increase the blood flow resistance.

Blood viscosity and other properties. If red blood cells, white blood cells, and platelets are excessive, the blood could cause huge flow resistance. The biggest risk is an excessive number of the large immune cells in blood. This could be a problem if several parts of the body are in inflammation or the whole body is in inflammation. Severe inflammation could raise blood flow resistance for the whole body. When the tissue is in inflammation, some of immune cells are retained, resulting in a reduced elasticity. If the situation is not improved, further retention of immune cells would quickly block local blood flow. We predict that flow resistance with free space (expandable space for accommodating additional immune cells) is doubly exponential with the total volume of retained cells. Blood circulation is nearly completely blocked if no free space is available. This is the main reason for difficulty to cure chronic diseases, cancer, etc. Due to those peculiar natures, blood viscosity and hydrodynamic properties are not sufficient measurement parameters.

Total amounts of toxic substances. Toxic substances such as immune suppressants interfere with chemistry of immune reactions. Other toxic substances such as carcinogens and other toxic substances would have similar but 
delayed adverse affects through altering tissue structure.

Blood flow driving force. The heart can generate enough force to drive blood passing through tissues, this property depends on the vascular system. This parameter cannot be based on any measured parameter, but reflect inherent capability or pumping power of the heart.

A good immune system must have (1) a good capillary network: a high density of capillaries (more capillaries per unit of cross-section area) and extensive distribution of capillaries in the tissue; (2) large capillaries pores (lack of fats deposit); (3) healthy cells and well ordered cell organization or high elasticity of the tissue; (4) a good blood composition (the counts of red blood cells, white blood cells and applets are in the right values); (5) lack of in-plasma toxic substances that can interfere with biological and cellular processes; and (6) a proper (inherent) blood flow rate or local blood pressure. In such a tissue, immune cells can migrate into the tissue, perform required immune function, and may move out of the tissue.

\section{B. The Model Can Explain All Risk Factors for COVID-19}

Those six properties well explain risk factors observed for COVID-19 patients in clinics, as below.

High age. Aging is associated with more dead cells, poorly functional cells, and damaged cells by nature. Because of high proportion of such cells in heart and all vital organs, heart function as well function of other major organs are diminished. It has double impacts: it reduces the heart's ability to maintain blood circulation and also diminish local immune functions in all parts of the body.

Lack of exercise. Lack of exercise is associated with reduced capillaries density, increased fats deposits in all tissues in the whole body. Those changes reduce the mobility of immune cells and thus impair all immune functions and tissue requiring functions.

Obesity (BMI $\geq 30$ ). Obesity means that more fats are deposited in tissues, blood vessels, etc. Fat deposit reduces capillary pore sizes, reduces the amount of deformable and expandable space, and reduces tissue elasticity. It increases flow resistance in any portion of the body.

Inflammation in any part of the body. Both acute and chronic inflammation can increase blood viscosity, degrade the blood circulation in organ tissue, and thus increase the risk of damaging vital organs. A wide variety of infections are known to cause damages to multiple vital organs. Increased blood viscosity 
decreases tissue perfusion or easiness of blood flow for the whole body and thus increases the risk of damaging the heart by myocardial infarction. An excessive number of red blood cells may cause vicious destructive cycle: Increased blood viscosity decreases renal perfusion and degrades the ability to supply nutrition (e.g., glucose and oxygen), which in term increases the secretion of erythropoietin which prompts for more red blood cells. It ends up with a worse result. Increased blood viscosity naturally increases the risk of developing thrombosis.

Low temperature. A low temperature at any local tissue causes the tissue to constrict. In addition, the low temperature also causes Central Nervous System to send signals to tissues to constrict. Thus, the narrowed blood vessels make it more difficult for immune cells to move through. In addition, if a tissue like those in the respiratory track is directly exposed to low temperature, the tissue rigidity is increased dramatically. The expected impact is increased risk of infection and rick of death.

Immune suppressants. Presence of immune suppressants in the blood fluid can directly interfere with biological and cellular processes that are vital to performing immune responses. Thus, dissolved ions of heavy metals, industrial organic compounds, small pieces of synthetic chemicals, etc. can suppress the immune responses by interfering with biochemical and cellular reactions. Those are immediate impacts that are in additional to the permanent effects that are realized by affecting cells and tissues.

The functions of all arms of the immune system also depend on a large number of specific biological reaction mechanisms. However, measures targeting molecular specificity will be explored elsewhere.

The above risk factors strongly support the model's validity. Additional risk factors that have been discussed by leading institutions [201] as follows:

Heart diseases. Vascular diseases affect disease outcome by altering heart functional reserve, and impairing immune cell migration.

Diabetes. Diabetes normally associated with poor micro-vascular network and poor energy metabolism.

Organ transplant. Increased risk is due to use of immune suppressants.

Chronic lung disease and Asthma. This class of diseases affect oxygen delivery, energy production, and lung reserve function. 
Blood or bone marrow cancer. Those type of cancer affect immune cells quality, and blood viscosity and hydrodynamic properties. They also affect the tissue-repairing functions.

Liver diseases. All digestive track related diseases affect energy balance, fats distribution, etc. and thus indirectly affect immune functions.

Renal diseases. Renal diseases affect the body's ability to remove toxic by-products.

Comorbidities and multimorbidity affect immune functions by respective organs involved and though inflammation they cause.

Pregnancy. During pregnancy, the immune system undergoes important adaptations to accommodate the immune tolerance required by the mother to carry the allogeneic fetus; however, these adaptions induce a potentially dysfunctional response to infections, as compared to the non-pregnant state [219].

Smoking. Smoking can damage organs and suppress immune functions.

Conditions affecting brain or nerves. Those conditions affect hormones that regulate the immune system (there may be other undiscovered mechanisms).

\section{The Model Can Explain Disease Patterns and Healing Miracles}

This immune functional capacity model can explain nearly all instances of disease patterns we have tried.

(1) Family member health patterns. When family members eat similar kinds of foods, share common things, and follow same health culture, they have similar exposure to toxic substances and infectious agents or microbiota, and tend to do similar life activities and share similar thinking habits.

(2) Common diseases in communities or geographic locations. The elevated risks may be attributed to shared water, air, polluted food, and common activities, and some disease agents may be from same food menus, cultural activities, etc.

(3) Old persons. Due to diminished organ functional capacity, they are more sensitive to disease agents such as virus and bacteria. Each instance of diseases can be triggered by something disturbing the balance of the immune function.

(4) Most illness can be explained by daily life. A vast number of diseases 
are triggered by exposure to cold temperature, bad foods or meals (unknown toxic or allergic compounds, often at undetected levels), bad drinks, emotional distress, exposure to infectious agents, overeating or starvation, fatigue and lack of sleep, exposure to bad environmental factors, etc. While regular health problems appear not important on the face, they slowly affect long-term health by cumulative effects. Personal illness outcome can differ dramatically because certain relevant biological resources determining major organ's function would differ by huge margins.

(5) Since each health problem or disease is mainly or in part caused by a large number of toxic substances, a solution to root out the disease must include avoidance of the toxic substances that the person is exposed to.

(6) When a person is exposed to hundreds to thousands of immune suppressants and other toxic substances, a large number of non-causal factors can affect the immune functional capability in real time. Thus, they are relevant to the outcome of the diseases. In a fight against cancer, the primary mission is to identify all cancer-causing agents, and take other measures to boost the immune system's real-time capacity.

(7) This model also implies that no drug or treatment can address those disease agents as effective as voiding them; and few medical treatments can boost the immune system, but they may be used as measures for managing acute symptoms and emergencies.

(8) This model can explain the observed cancer self resolution cases. Cancer survivors often completely change their lifestyles. This is a way to cease exposure to the same cancer-inducing agents. The model also explains why a large number of things that seem to have nothing to do with cancer could help. Doing things to forget the cancer, singing songs, placing themselves in a happy environment, changing daily activities, changing jobs, changing residence, avoiding being exposed to same infectious agents, etc. all have predicted beneficial impacts on cancer containment and self-resolution. Even change in environmental temperature could be a significant factor.

(9) This model also shows that past measures by cancer survivors are often incomplete. Many survivors may have used only one or a few all potential measures, but our model shows that both causal factors and immunesuppressing factors must be addressed. This model also implies the need to use weak factors with current impacts on the immune capacities in addition to factors having long-term effects. In addition, complete measures should be expanded to include factors in emotion/mind, diets, avoidance of toxic 
substances, activities, environmental factors (including climate), thinking habits, etc.

\section{The Model Can Explain the Effects of Unrelated Life Factors on Im- mune Functions}

We will show that the immune function is always coupled with the vascular system, garbage removal function, and tissue repairing functions so that any life factors affecting those three functions must affect the immune functional capacity.

\section{Vital organs affect the immune system performance}

Some immune cells are not found in blood. Possibly, they change their properties upon entering tissue. One example is macrophages, which derive directly from fetal progenitor cells, mature in tissues such as the lungs, liver and spleen. Others, such as memory T cells, develop from activated T cells that migrate to tissues after they have been primed in lymph nodes during an infection. These tissue-homing $\mathrm{T}$ cells take up long-term residence in tissues and can develop properties that are distinct in each. This is perhaps the main reason that immunology pays little attention to tissues that are not the primary site of disease [174].

We found a compelling reason to consider the whole body tissue. First, the outcome of all diseases are manifested in heart performance; and a large number of additional life factors such as activities, whole body flow resistance, body temperature, etc. affect heart functions. Indeed, heart functional reserve is a determinant factor for the death threshold in nearly all cases. The immune system's performance cannot be evaluated without considering those factors. Second, the immune system is tightly coupled with renal function to eliminate garbage, the liver's function to provide energy and the lung function to provide oxygen.

In a typical respiratory infection, a virus prompts dendritic (antigenpresenting) cells to migrate from the lungs to adjacent lymph nodes, where they prime virus-specific $\mathrm{T}$ cells, such as CD4+ T helper cells. The priming promotes B cells to differentiate and produce antibodies; cytotoxic CD8+ T cells are also produced, and migrate to the lungs to kill the infected cells and prevent viral spread [205]. Here, the two trips: dentritic cells travel from lungs to lymph nodes and the migration of cytotoxic CD8+ T cells to lungs tissues depend on vascular system and traveling channels. The ability to remove wastes also depends on renal function. Based on our prior studies, mobility of those immune cells must be a very important factor and all factors affecting blood flow resistance must 
play a big role in complications such as heart arrest, stroke and thrombosis [203a]. Our focus must be on both infected and uninfected tissues.

The exact migration path and mechanisms of immune cells are not fully understood, one thing must be true is that cytotoxic cells must reach any location where an infected cell might be found. Existent studies have not addressed two issues that are critical to disease outcomes. While lymphatic vessels transport lymph fluid away from tissues, they must move from capillaries and inter-cellular spaces. White blood cells must move through all peripheral tissues and then return to blood circulation. They change their forms when they enter tissues. Due to their large sizes, white blood cells must squeeze through much smaller capillaries and inter-cellular spaces. This implies that baseline flow resistance sharply depends on blood composition and tissue properties. After an infection has occurred, detrinctic cells move into the nearby lymph nodes, and cytotoxic CD8+ T cells move back to the lung tissue. To engulf an infected cell, the CD8+ $T$ cells must reach any location where an infected cell could be found. That is why we found that tissue elasticity or yielding property is crucially important. The strongest evidence is temperature effect: when tissue is lowered to nearly 10 ${ }^{\circ} \mathrm{C}$, immune function is crippled [118]. On average, dendrites measured 15-20 microns in length and 0.1-0.3 micron in diameter and occasional dendrites were extremely elongated, reached several hundred microns in length, and terminated in an enlargement measuring nearly a micron in diameter [206].

The current approach of focusing diseased organ is clearly inconsistent with reality. Routine laboratory data and clinical observations also imply that the elevated WBC must be considered globally. Normally, the total WBC count for an adult ranges from 5,000 to $10,000 / \mathrm{mm}^{3}$. Leukocytosis (WBC $>10,000 / \mathrm{mm}^{3}$ ) can indicate infection, inflammation and other problems [207]. When the body responds to an acute infection, many immature WBCs, called bands, develop. Normally making up 3\% to 5\% of WBCs, bands circulate for about 6 hours before they mature to neutrophils. The neutrophil count increased from the bands maturing may be caused by an infection. It is generally agreed that if WBC count is more than $11,000 / \mathrm{mm}^{3}$, it can be dangerous. The body's ability to tolerate increased WBC count highly depend on tissue condition. The effects of elevated WBCs count must be evaluated globally, rather than by focusing on just the diseased organ or tissue. For example, even if WBC elevation is caused by infection of nasal cavity or bronchi, the raised WBC can dramatically raise systemic blood flow resistance for any part of the body and adds burden to the heart. 
The nature of interactions between the immune system and organs can be attributed to dominantly parallel-flow circuit pattern of all major organs. Increase in blood flow resistance in any organ must raise the systemic blood flow resistance (e.g. systemic vascular resistance). Thus, the blood flow resistance raised by a diseased arms or legs must raise the systemic blood flow resistance and affect the functions of the lungs or any other organs.

In a lung infection, elevated WBCs, retained WBCs in tissues (may become other forms), and returned B and T cells from nearby lymph nodes can also use up extensible volume in the tissue. Thus, they raise blood flow resistance for the whole vascular system. In addition, the ability to remove garbage is also a shared function of the renal function, the total effect of which is time-dependent. In addition, tissue repairing function, unlike the preventive arm of the immune system, is also time-dependent. The immune system can remove more waste and repair more damages in a longer time. This means all life factors in the entirely relevant times affect immune functional capacity. The effects of each life factor can be explained by examining how it affects any of the six properties.

\section{Examples to show how unrelated factors affect the immune functional capacities}

Body massage affects cancer outcomes. Whole body massage is used in ancient medicines. Even though it appears to make little sense, it can be explained by our model. Massage can improve tissue elasticity and improve the local blood circulation. The total blood flow resistance depends on the resistance in all tissues which are connected largely in parallel "circuits". If for any reason, the body demands a higher heart output, the overall resistance experienced by heart would depend on the flow resistance of each tissue. If most of the body parts have low flow resistance, the heart can run with a lower work and has a lower chance to fail. In a second scenario, if any part of the body is under cytokines storm attack, the storm may provisionally raises the infected tissue's resistance (ignore its impact on other tissues for the movement), all peripheral tissues are like a bypass for maintaining blood flow so the heart will not experience excessive resistance. For a person with good tissue condition, if his normal blood pressures are 80/120, they would become 90/210 when a cytokines strikes. For a person with poor tissue, his normal blood pressures are 90/160, his blood pressure would become 100/310 if a cytokines strikes. The high pressure may cause heart attack, heart failure, heart arrest, stroke, or thrombosis. For nearly all diseases, the final failure or cause of death is always related to the heart. Even though massage has nothing to do with cancer, it can dramatically affect the patient's ability to withstand complications and vascular events by 
affecting terminal tissue's flow resistance. Such measure is like increasing the margin for reaching a death threshold. If the majorin is $30 \%$ of the total maximum heart function (100\%), such measure would dramatically extend the patient life. This can be proved by doing a simple mathematical simulation.

Physical activity favors cancer resolution. All solid tumors have a common feature that the tumors are congested with immune cells particularly macrophages. The immune cell mobility may be an important factor (in addition to all other benefits of exercise). If the tissue is often active with physical activities, it would be harder to have immune cells retained. Singing can dramatically reduce the risk of getting lungs cancer and many lung diseases; and tumors are far less frequently seen in body parts that are involved in active motions. Physical agitation facilitates immune cells to move through and may also discourage cell division.

Ten happy moments vs. ten stressful arguments each day. Most existing studies are based on clinical trials or long-term follow up, they could not detect weak effects. However, this can be seen from how it affects tissue cell organization. When one is happy, the body is in a relaxing state. Each instance of relaxing has extended impacts on the tissues. If one repeats happy moments, his body tissues will be more likely in a relaxed state. The body state also interacts with CNS signals [199]. In contrast, repeated confrontation or stressful arguments can cause the body to produce more stress hormones. Excessive stress hormones release results in blood vessel narrowing and more tightly packaged tissue, and thus deteriorates blood perfusion in the tissue. Repeated arguments will make this problem worse because the constricted state will be accepted by CNS as the normal state. For certain people, high blood pressure can be best managed by relaxation exercises.

The Voodoo Spell. Extreme worries do not directly cause cancer, but have great adverse impacts on the immune system's ability to prevent and fight cancer. Excessive or long-lasting worries can alter the hormone secretion patterns which can profoundly alter tissue properties and cell organizations in the tissue. The eventual lack of energy and accompanied accumulated toxic metabolic by-products may cause heart muscles to lack power to pump. The hearts in some situations are unable to maintain beats. Our prediction is consistent with findings that depressed and last anxious mood are associated with decreases in lymphocyte proliferation and natural killer cells activity, as well as changes in the numbers of white blood cells and the quantity of antibody circulating in the blood [208]. 
Hygiene habits and diets. Microbiota has recently attracted intensive research interest. The CNS, gut microbiota, and the immune system interact among themselves. Some gut microbiota may produce toxins which damage tissues and thus suppresses the immune system. Sometimes, poor personal hygiene habits may be responsible for asymptomatic infection by harmful microbes or dormant harmful microbiota. To revolve cancer or other diseases, one must find a way to prevent the infection or alter the gut flora. Habits of cleaning reusable tea cups and changes in diets may alter gut flora and thus resolve the cancer.

Obesity, fats deposit, and physical occupancy. Fats deposited on blood vessel internal walls can reduce the amount of spaces for expansion and increase resistance of immune cell migration in tissues. The free or expandable total space inside the thoracic cage is the most important factor.

Anything that affects blood hydrodynamic properties. The number of red blood cells, the total number of white blood cells, the presence of other large particles, the amount of fats, and other viscous materials and compounds can increase the resistance to blood circulation. The two most important determinants of blood viscosity are the hematocrit and fibrinogen levels. The lowering of the hematocrit can increase cerebral blood flow. Platelet aggregation is also an important factor. Vascular damages and injuries in any part of the body can increase blood viscosity.

Chronic Stress. There is a relatively large decrease in both lymphocyte proliferation and natural killer cell activity in individuals who have experienced stress [208]. A similar result is found for examination stress: A severe stress reduces white blood cells counts in plasma with an exception that an increase in platelet and neutrophil count is observed [204]. With more anxiety, fewer antibody is produced. Acute increases in stress hormones such as cortisol and epinephrine are related to decreases in the number of white blood cells in circulation, decreased lymphocyte proliferation, and reduced natural killer cell activity.

When the body is under stress, the constricted tissue captures and retains more of the WBCs dynamically [204]. Thus, retained WBCc cause blood pressure to rise. When the spaces in capillaries is narrowed, it could be harder for antibodies to bind viral particles for eventual destruction by T cells. In addition, space restriction is most probably a factor affecting $T$ cells function in shipping out digested cell waste. 
Meditation benefits. Meditation is found consistently to help in fight against lung infection [197]. Its biggest impact is through expanded immune cell migration channels because meditation is aimed to achieve a "total relaxation" [197] as compared with flight-and-flight situation, a constriction. When the body is in a total relaxation, immune cells can migrate more easily, thus have larger capacity for removing garbage and repairing tissue damage. This explanation is consistent with the finding that an increase in epinephrine and other hormones actually result in a better outcome [as findings in 204, 208]. In the body with relaxation and deep breathing, stress hormones alone do not determine their final net effects. Their final effects are determined by what the stress hormones are raised for: to help achieve relaxation or prepare for an actual fight.

Personal activities. The final outcome of immune system's failure is nearly always reflected in organ failure. Most deaths are caused by heart failure or heart-triggered complications. Then, personal daily activities must be big influencing factor because they can add one to several times of pulse pressure to the heart. In addition, the body position can alter local pressure inside the brain by more than $50 \mathrm{~mm} \mathrm{Hg}$. In addition, sudden motion of parts, sudden stop of the body, and change of body position are known to be associated with stroke. All physical activities and environmental factors can affect local blood pressures inside the brain. Personal life activities can affect kidney health by controlling hydration level and urination frequencies. In addition, personal behavior is the most important for avoiding viral attacks [192]. Even the use order of same foods or different distribution of calories among the three meals can result in different calories balance.

It is clear that all second classes of factors are applicable to all diseases such as cancer, heart disease, COVID-19 and AIDS. For AIDS, the disease agents are HIV (with limited roles) and perhaps massive immune suppressive factors. For COVID-19, the disease agent is SARS-CoV-2 virus, but disease outcomes depend on all immune suppressing factors and many factors that appear to be unrelated to the immune system (due to shared organ functions, shared tissue repairing function and shared garbage removal function).

\section{Seemingly unrelated factors can make differences by affecting the sophisticated balance of the immune system.}

Immunology has become a complex science, and produced a large number of conflicting findings for similar situations. One weakness of using clinical trials is the inability to consider personal differences. Based on cited studies in view of the six classes of properties, we propose a dynamic balance theory below. 
The core presumption is that the immune system must be maintained in balance. Our first assumption is that the best immune system is one with highest immune cell mobility and powerful immune surveillance capability. Whenever a pathogen attacks any part of the body, the patrolling immune cells are able to find them, mark them, and have them destroyed rapidly. If this condition is met, the immune system does not need to start acquired immune response, and there is no need to use a large number of B cells, T cells, etc. which could be dangerous to the host tissue. The body can win its fight in the earliest stage of invasion. In this case, cytokines cannot pose a meaningful threat and the immune response cannot cause immune-mediated damages. Any exposure could be effectively addressed by suitable arm or arms of the immune system.

An ideal immune system is one with great blood micro-circulation in all parts of the body, backed up by healthy heart, kidney and liver. Such an immune system has the capacity to fight a larger number of pathogens. It can respond as fast as possible, and yet will not over respond after it has started its acquired immune response.

In contrast, two kinds of poor immune systems are frequently observed. The first kind is one with poor immune surveillance functions. One key feature is poor micro-vascular networks. In such a person, the immune cells are unable to reach all potential locations in tissues. Even if they can, it may take too much time to complete it. In addition, the ability to remove metabolic wastes and repair damaged tissues is also limited. The immune system cannot contain very limited number of seed viral copies and may take longer time to recover from very light infection.

A second kind of poor immune system is a suppressed immune system with poor organ functions. Immune suppression can be a serious and prevalent problem for modern people. It poses a unique problem for lungs. If a massive number of viral gene copies attack the internal surface cells of lungs simultaneously, the virus could cause severe damages to lungs before the immune system even has time to generate neutralizing antibodies. This problem is very unique for lungs because the virus travels through internal air channel structure but not through a media circulated with blood. The second problem is that such an immune system can cause an excessive immune responses, thereby causing extensive damages to vital organs such as lungs, heart, kidney, liver, or the brain. This can be caused by a temporarily suppressive effects of any factors in the early stage. When the immune suppressive effect is gone or when the accumulated virus copies force the immune system to respond, the immune system starts an excessive response. 
The main causes of damages can be traced to (1) exposure to a large number of infectious agents, (2) a temporary suppression of the immune system, (3) compromised immune function, or (4) a combination factors of all them. Bad exposure is unique in lung infection because all lung cells are exposed to internal air ways, and thus the time for spreading the virus can be so short that even an immune system in a healthy person could not contain the virus. Very little can be done for this problem other than avoiding excessive exposures. A belayed immune response is the only way to overcome the virus. Due to the delayed response, the virus is able to replicate to reach a large number of copies. The widespread viral infection ultimately results in a massive number of $\mathrm{B}$ cells and $\mathrm{T}$ cells, and thus cause excessive tissue damages. Outcomes highly depend on the severity of exposure, the suppression of the immune function, and the organ's functional capabilities.

Boosting early immune response and mitigating later immune damage are the main purpose of interventions. From kinetic point view, this can be achieved by reducing the viral amount in the initial exposure and eliminating immune suppressive factors in the earliest times. The immune system may be suppressed by permanent factors, temporary factors or both. Permanent factors, which cannot be corrected quickly, include cell aging, cell damages, blood vessel blockages, fats stored in tissues, presence of persistent toxic substances in plasma, etc. However, a much bigger immune suppression is actually caused by a large number of temporary factors. Those factors can be corrected easily. Those factors affect the immune system through all of the six classes of properties. In addition, those factors can also temporarily burden, consume, or impair the organ's functional reserves.

By altering all relevant factors by looking at their effects on the six classes of properties, it is possible to (1) speed up immune response, (2) improve ability to contain viral replication and thus reduce the number of viral copies in the infected organ, (3) enlarge the capacity of removing garbage from infected cells and immune cells, and (4) improve the capacity to repair damaged tissue and remodel diseased tissues. Temporary suppressive effects can be eliminated by avoidance and changes in daily activities, and permanent suppressive effects in the immune system may be partially corrected by a long-term plan.

We propose, based on overwhelming study findings, that immune system must be maintained in an exact balance. We regard tissue health or disease state as a reflection of all historical effects of both disease processes and the repairing processes. The tissue health or disease state is also reflection of all historical current states in the person. We also regard the body's defense capability as a 
reflection of the relative strengths of exposed disease agents and the immune system's current defense capabilities. Since disease process, garbage removal process, and tissue repairing process operate in a continuous basis, any small perturbation could make differences to disease outcome.

Extra metabolic wastes from other diseases may make the garbage disposal function fail. Additional demand for the heart function of any other sources may cause heart failure or stroke that could be prevented without the demand. The number of white blood cells entering an infected tissue must be same as the number of the cells exiting cells. If immune cells have degraded in the tissue, the generated wastes must be shipped out of the tissue in time. Based on our prior simulations, if the immune system is unable to maintain immune cells transport balance, immune cells can quickly accumulate, resulting in inevitable failure of lungs. This appears to be an absolute requirement.

If an excessive number of immune cells are dynamically retained in the infected tissue, it is impossible to repair damages in the tissue. When too many immune cells are retained, further immune response can cause more and more damages because additional immune cells are congested in the tissue. The failure of the immune system depends on six classes of factors (particularly blood vessels and tissue elasticity), the renal functional capacity, liver health and the whole body health. The abilities to deal with a severe infection would be very different among different persons. Some people may run the immune systems at much higher B cells and T cells concentrations without any problem, while others may suffer severe immune pathological damages even at moderately high B cells and T cells concentrations. Differing failure points imply that conclusions from population studies cannot be applied to a specific person.

In addition, the immune system must maintain a rough balance between the speed of destroying infected cells and the speed to fill voids from killed cells especially if infection is on a vital organ. If the immune system is unable to keep this balance, the tissue has insufficient number of functional cells and the organ might fail to support life. Personal ability to tolerate missing tissues is predicted to depend on the organ's functional reserve, the amount of infected cells, and cell quality in the uninfected region of the organ. A fast tissue-repairing capability is important for resolving the disease.

We also found that a disease outcome cannot be predicted reliably by looking at cytokines and any single arm of the immune system. One obvious example is the role of stress hormones, which are often considered as bad. However, what is really bad is when they are run constantly without breaks, or 
they are released at excessively high concentrations to actually prepare the body for a fight or to deal with emotional pain.

\section{Explain the benefits of healing exercisers}

The benefits of many exercises cannot be predicted by looking at single factors, as shown in studies involving deep breathing exercise and meditation. The utilities of stress hormones are developed in evolution. The use of stress hormones, as they are used in nature, is considered as good [81]. What is bad are hormone are secreted at excessively higher frequency, or at excessive amounts to deal with an excessively high frequency of dangers. Meditation raises some stress hormones, but causes total relaxation, rather than constricts the body and prepares for a fight. Meditation improves glucose metabolism and increases immune cell mobility.

Deep breathing exercise, meditation and other mind-body exercises share two common elements: achieving relaxation and achieving calmness. The exercises expand immune cell traveling channels, improve glucose metabolism, and reduce the burden on the heart. Yet, the body is not prepared to fight, flight or solve complex puzzles. This results in an artificial state that the energy is in a great surplus. Yet, calmness and relaxation induce the person to enter a state for getting rest, removing garbage, and repairing tissues. This is a state next to sleep, the purposes of which are resting, repairing and maintenance. Since the body is not to deal with external dangers and solve complex problems, it can immobilize all biological resources such as energy, materials, the CNS's attention, etc. for removing garbage and repairing damaged tissues. Moreover, the person generates the least garbage from his baseline metabolism, and thus has a greatly improved capability to remove garbage and performs tissue repairs. This explains positive findings without conflicting roles of single factors, hormones or cytokines. Thus, a differentiating factor is what the stress hormones are used for. If it is used to create a situation for enhanced tissue maintenance and repair, it is good.

By using the above analysis, we can predict how slow and deep breathing exercise affects health and diseases. Based on the summary data from Rosso et al. [209, with original citations omitted], slow breathing has the following effects:

1. Generally increased tidal volume and enhance diaphragmatic excursion;

2. Enhances ventilation efficiency and arterial oxygenation via alveolar recruitment, and distension and reduction of alveolar dead space; 
3. Increases venous return, increases filling of the right heart, increases stroke volume, and increases cardiac output;

4. May decrease mean blood pressure;

5. May alter and enhance vasomotion and microflow and improve blood oxygenation;

6. Improves pulmonary gas exchange efficiency, minimizes cardiac pumping work, and buffers blood pressure fluctuations;

7. Increases vagal activity (the vagal tone);

8. Shift towards parasympathetic dominance;

9. Improves autonomic responsiveness to physical perturbations (i.e. standing); and

10. Optimizes sympathovagal balance.

Slow breathing has complex physiological effects. It improves oxygenation, improves carbon dioxide elimination, and enlarges heart output at a lower mean blood pressure. It improves micro circulation in tissues. The body state that slow breathing creates is similar to what is created by meditation, where the practicing person is in an improved energy state, but the person is NOT using the energy to perform stressful tasks like running away from a tiger. It must create a most favorable environment for performing basic immune function, removing garbage and repairing tissues. If there is a viral attack, the tissue is in a better energy state to counter the virus. One important point is when the body improves energy state, it also activates parasympathetic dominance which favors resting, nourishing, and repairs. That means that all biological resources can be readily used to get rest, digest foods, enlarge blood vessels, and create a stressfree body environment. It is the best state for conquering a disease.

Our energy/resource usage analysis can be applied to mind-body measures. The mind-body exercises are even more complex because they are involved in motion, deep breathing, focus, relaxation, sound uttering, induction, etc. A large number of such measures have been developed in ancient times, but their mechanisms are poorly understood. The representative exercises include Tai Chi, Qi Gong, meditation, Yoga, martial arts, other healing exercises, which could be used as a major component of interventions. Their positive benefits are generally beyond disputes [217]. They play an important role in regulating the immune system and reducing inflammation. In addition, some cited studies suggest that 
some measures may increase virus-specific, cell-mediated immunity at rest and in response to vaccinations [217].

By using our energy/resource usage analysis, it is not difficult to show how each of such exercises beneficially affects the immune system. We note that in all of those above examples, most health benefits are also applicable to the vascular system. For example, they can increase heart output at the lowered cardiac work and lower mean blood pressures. Thus, the evidence naturally shows they can have beneficial role on the vascular diseases.

\section{E. The Great Significance of All Life Factors to Disease Outcomes}

We have shown that garbage removal, tissue repair, and tissue remodeling are shared by great degrees, and that liver, lungs, heart, and kidneys are shared global biological resources for fighting all diseases in each person. In many times, a single factor could determine disease outcome as shown in the following impact scales: (1) temperature could alter local blood flow rate by up to 20 times [118]; (2) exercise could change cancer survival rates of many types of cancer for various survival years by nearly $40 \%$ [54-65]; (3) personal body position could change internal local blood pressure inside the brain by more than $50 \mathrm{~mm} \mathrm{Hg}$ pressure (one meter water high is $73 \mathrm{~mm} \mathrm{Hg}$ ); (4) warming foot by a warm bath can raise blood flow rate by many times at reduced heart work (Implied by 118); (5) most drugs' current impacts could be more than 10-20 times of their lasting baseline impacts (referred from half lives); (6) food poisoning and subtle toxic impacts must be very large (based on severe symptoms); (7) a demand triggered by any factor could generate 20 to $80 \mathrm{~mm} \mathrm{Hg}$ additional burden to the heart (rough estimate based on pulse pressure), and (8) a bad argument in a wrong environment and wrong time may be a game-end mistake (a common factor for triggering stroke). Sometimes, one single factor may have the power of checkmate in ruining personal health.

Since all vital functions are influenced by both current effects and permanent effects of a large number of life factors, the effects of all influencing factors are naturally additive (most probably in non-linear manners). Current effects can slowly alter cell health and tissue structures, thereby exerting long term effects. The overall capabilities of garbage removal and tissue repairing functions may be roughly expressed as time-averaged current functional capabilities over a relevant time period (Line D in FIG. 3). Based on indications of kinetic data of a large number of substances and influence factors, we estimate that the overall immune capabilities may be only $30 \%-80 \%$ of the maximum values. It is even possible the immune system is too tired to fight. We can safely assume there are HUGE rooms for boosting the current functional 
capacities, and there are fair rooms for enlarging the potential immune functional capacities and organ functional capacities.

The effects of life factors can also be explained by their accumulative effects. All biological processes operate on a continuous basis. All factors affect personal health or disease state by influencing all biological processes by accumulative effects over the entire time period. All historical effects of all life factors are recorded in the tissue. All variables such as toxic substance numbers, their relative concentrations, and their histories are reflected in the historical damages in tissues. Indeed, most diseases (particularly cancer) are caused by only a small imbalance in some biological processes. Now, a patient has $\mathrm{N}$ causerelated factors and $\mathrm{M}$ seemingly unrelated factors to use in fighting any disease. Any claim that chronic diseases are incurable by nature cannot be correct. The concepts of using two sets of life factors are applicable to cancer, heart diseases, AIDS, COVID-19, rare diseases, etc.

\section{DISCUSSION}

Without understanding the dynamics of the immune system, patients are unable to alter exposures according to his unique immune functional fluctuations timings, and unable to use personalized ways to fight against infectious agents and chronic diseases. We have shown that each person has distinctive time windows at which they are more vulnerable to the attacks of disease agents. The best strategy is avoiding creating immune-suppressed time windows, reducing big immune suppressive valleys, avoiding exposure to disease agents in the time of immune functional capacity valleys, and raising overall immune functional capacities. The highly dynamic nature of the immune functional capacities implies that best preventive measures must be tailored to the personal immune system's changes. This is very similar to military actions: the final victory often depends on how two sides' maneuver rather than on troops head counts and weapons counts.

Our immune dynamic balance theory implies that the immune functional capacities in a time period for a person is distinctive and is controlled by personal life activities, exposure to toxic substances, diets, emotional state, personal health, etc. Overall immune functional capacities, a specific arm's functional capacity, or the overall immune system's capabilities for removing garbage and repairing tissues in a given time period are periodically changing. There are no fixed immune capacities that can be used to represent the person 
and such an average is generally meaningless in light of the large number of big influencing factors we have identified. A particular immune functional capacity of an 80-year old person at a given time would be completely different from that of a 20 years old woman on the same time. Due to large fluctuations in immune functional capacities, it is clearly improper to evaluate personal immune system like a "fixed constant" or "an extensive property" for all persons.

The effects of life factors on the immune system must be evaluated by two separate impacts: their immediate impacts and their long-term slowly delivering impacts. The immediate impacts are highly dynamic often with very large fluctuating amplitudes. Thus, evaluation of immune function performance by merely looking at disease incidences and disease severity as a whole is insufficient because such an approach cannot enable patients to fight disease agents and diseases according to the conditions of their immune systems.

The existence of dynamic immune functional capacities implies that the most powerful approach to challenging chronic diseases is outside medicine. Drugs, surgeries, radiation, and devices cannot help much to improve the permanent immune function capabilities and the current immune functional capacities. For example, the root cause of cancer is exposure to one or several key cancer-inducing agents while the inability to resolve cancer can be attributed to all immune suppressive factors. Immune suppression can be traced to potentially thousands of factors in mind/emotion, environment, activities, nutrition and diets, and exposure to toxic substances. An alternative approach to cancer treatments is mitigating all cancer-inducing substances and restoring the current immune functional capabilities. Our model proves the validity of the lifestyle change concept and justifies the need to use life factors to boost the immune system's current functional capacities.

According to current literature, the immune system includes white blood cells, lymphatic system, spleen, bone marrow, thymus, complement system; and secondary lymphoid organs include the lymph nodes, the spleen, the tonsils and certain tissue in various mucous membrane layers in the body. Body tissues are not considered as a component of the system in immunology. We think that tissues should be regarded as the primary lymphoid organs. The tissues are the battle grounds of all immune cells and the targets of immune actions.

Chronic diseases including cancer and personal ability to survive from COVID-19 disease are influenced by $\mathrm{N}$ and $\mathrm{M}$ factors, $\mathrm{N}$ represents the number of factors related to disease agents and causes, and $\mathrm{M}$ represents the number of factors that influence the immune functional capacities and organ capacities. For cancer, both $\mathrm{N}$ and $\mathrm{M}$ are very large. Most of causes-related factors are caused 
pollution while most of $\mathrm{M}$ factors can be attributed to overwhelming social practices that formed after The Industrial Revolution. Frustration from lacks of help, failures and losses, restrictions and conflicts fall on all people on a daily basis. Due to big delays in understanding the health-ruining culprits and disease causes, mankind has created enough poisons, and toxic substances that will have enough power to wipe out species from the planet. Moreover, mankind has created enough health injuring practices to cripple the immune system from fighting such diseases. Mankind is approaching a checkmate for its own existence.

Our multiple disease causes model refutes the validity of "Independent Action Model", by which drug side effect of each drug or chemical is determined independent of other drugs and chemicals. By using this deeply flawed model, researchers only look at those that may cause exposure exceeding allowable daily limits. By failing to consider additive effects of all toxic substances, society grossly underestimates the total adverse effects of all pollutants and toxic substances on the planet by hundreds to tens of thousands $(100-10,000)$ of times. By relying on this obsolete model, each single chemical is considered safe, but species are rapidly extinct. Now, cancer and chronic disease are found in pets, fish, birds, wildlife, etc. and strike newborns, teens, and young people at twenties and thirties. Sudden death can happen among teens, high school students, and college students. Population health data in developed nations and developing nations have revealed disastrous trends that should have prompted serious rescue missions a long time ago. After the huge number of man-made chemicals have dispersed into every corner of the planet, there is no hope that miracles will allow humans to survive. Extinction rates for other species today are much higher than background rates. Societies cannot wish miracles saved human species, and must divert primary activities from doing business to rescuing operations for human existence.

It is projected that total medical spending in the U.S. will rise from $\$ 3.205$ trillion in 2015 to $\$ 3.358$ trillion in 2016 , then $\$ 3.539$ trillion by $2017, \$ 3.965$ trillion by 2018 and, ultimately, to $\$ 5.548$ trillion in 2025 . There is a clear exponential trend in the spending rise [225]. Overwhelming health problems in the U.S. are discussed [13]. The pandemic will make reality much worse. The population health is expected to fail when massive disease agents and massive stresses strike all people in combination under our disease multiple causes model, eventually reaching a catastrophic health failure point.

The complete solution includes fixing environment and mitigating common stress for the population. The idea of winning a top ranking, wining a 
championship, getting a title, or winning a metal has gained wide acceptance long before their destructive force of high stress to health of contestants was known. The value and contribution of each winner is artificially created at the cost of producing millions of victims with lifetime damages to their health. Even winners often suffer life-time injuries and even premature deaths. By observing some athletes in the 2021 Olympic Games, we noted that some contestants are full of scars and injuries in their legs. Contestants tried to attend their pain after they fell off on ground, the balance beam, or uneven bars, etc. Some contestants get handicapped from injuries from accidents. Only winners are those sponsoring companies that use the opportunities to generate revenues. Bull fight was considered as good entertainment game in barbarous societies where duel and killing was acceptable. Olympic Games have gained acceptance long before the severe adverse impacts of extreme and regular stress from the intense competition were known. Its past wide acceptance should not preclude for reconsidering their true social benefits. Potential reformations include rewarding more contestants, minimizing the awarding impacts based on different ranking, and eliminating high risk events.

The competitive grading system in schools should be deeply examined. The old generations have gone through the process with ultimate costs to their health and huge burdens on national economy. Twenty years of extreme school stress in a vicious inhuman competition setting may ruin a big part of their lives or half of their health. If the old people had known how their school stress might have altered their life and enjoyment, some of them might have chosen different paths. Most young people do not know the detrimental role of excessive and lasting stress on a daily basis. If they were told of the truth, some of them might make different choices. This is the most important matter for them when chronic diseases and cancers are about to strike every person on the planet soon. While truth has come with delays unfortunately, society should let the young generations understand the adverse impacts of excessive high stress that torment them on a daily basis.

Other health-impairing culprits include professional licensing examinations, employment examinations, abusive examinations for all kinds of purposes, promotional competition, violent shows in TV, endless drug commercials, and commercial practices intended for monopolies. Most healthruining practices have gained popularity after 1940 and promoted by junk science such as ranking method, etc. Society needs to weigh their social benefits against their real harms to all people and the whole society. After going through COVID-19, under the harsh climate, having exposed to massive toxic substances, the young generations will not have much organ functional reserves to tolerate 
large and enduring stress as the old generations. While society can do very little to undo the harms that the old people have absorbed, society should think how to protect the young generations. The right to choose between health/survival and corporate profits should be on the involved persons. The reality should be considered in light of the fact that massive man-made chemicals are dispersing to every corner of the planet, and cellular phone misuse culture adds another big heath damaging effect on the young generations.

This immune system dynamic model can explain the sophisticated dynamic balance between different immune processes. The immune cells must be in a proper range to be good. Too little of them can cause inadequate immune response but too much of them (particular T cells) can cause immune-induced damages. Similarly, production of stress hormones can be good and bad, depending on duration, relative amounts, circumstance, etc; delayed or weakened acquired immune response and excessive immune response are inherently bad. However, some factors are predicted to be good: a large organ capacity, well distributed micro-vascular networks, and lowest amount of toxic substances. This means that many life factors can be used with confidence on nearly all people.

The large scale of changes in the immune functional capacity implies that a person can manipulate the immune functional capability in fighting infection. Based on personal experiences, initial infection location of cold and flu is often localized, with noticeable time delays in spreading the viruses. The initial signs may be in a left nasal cavity, a right nasal cavity, the throat, bronchi, deep bronchi, etc. It takes several hours to spread from the left nasal cavity to the right nasal cavity. Generally, it takes several hours to one full day to complete the spreading process from an earliest local infection to a fully developed cold or flu. This means that a person has at least 6 hours to one full day to alter the personal current immune capacity to mitigate an incoming infection. Some measures include restoration of body temperature, taking a warm bath, taking hot feet bath, consuming heat-generating foods (such as Ginger), inhaling warm air, etc. Those measures can rapidly improve immune system's current immune functional capacities.

By using a personalized health optimization model, we would use different approach to containing the COVID-19 pandemic [200, 202-203]. Based on risk factor [201], the focus would be on those vulnerable people because $80 \%$ people do not expect to experience serious complications. At this point, medicine has no cure for the disease [220]. While the benefits of mRNA vaccines was found to be more than $90 \%$, most researches could not take into account the beneficial role 
of temperature which could cause 10 folds difference to incidence and death rates $[121,118]$. When the cold season strikes, temperature will be a superstrong aggravating factor. Soon, Delta variant will strike the U.S. In addition, Nepal variant is gaining momentum to reach all parts of the world [222]. We predict that the worst pandemic outbreaks will strike the world. There is no fast and simple solution like pills. Routine big fluctuations of human immune functional capacities imply a realistic path for conquering the disease on a personal basis.

All debates on vaccine benefits and disease risks cannot be resolved without understanding the deep flaws in population-based approach, statistical model, and side-effect evaluation model [1-2]. Those flaws and interference of life factors can have research biases of failing to find at least $99.9 \%$ of long-term side effects. The population approach, if used to evaluate weak factors, is wrong because it assumes that health property can be studied by using a statistical distribution, which did not exist [2]. All population studies also violate the rule against using intensive properties OUTSIDE each system. The flaw is like getting an average of fuel consumption rates for a small car and a big truck, and then apply the average to both, naturally crippling both, and most side effects are hidden due to a large amount of organ functional capacities (biological functional reserve is 10 to 1000 times larger than what is needed to support life) [113-115, 187]. Without addressing the deep flaws in its research models, its conclusions do reflect reality and facts-checks [221] are unable to detect inaccuracies introduced by research models.

\section{LIMITATIONS OF THIS STUDY}

This study is based on factual findings in the whole field of medicine and public health because a holistic health model means to cover everything under the Sun relevant to personal health. While only selected references are listed in References, reliance has been made on research articles that are not listed and things we know personally. We believe that our immune functional dynamic model and analytic methodology can be trusted due to the huge amount of evidence. Due to the broad coverage of subjects, we could not address a vast number of less common factors such as using cellular phones, body vibrations, genetic modified organisms, etc. It is impossible to cover everything in this first article. One big limitation is that most chemicals ( $>97 \%$ ) have not been studied (even current safety data cannot be trusted due to reliance on the independent 
action model, insufficient study duration, and wrong side-effect study method. If the full truth is included, the actual danger in front of mankind may be much bigger than what we predict based on currently available data. Society should not be constrained to those factors expressly discussed in this article. We hope public interest research groups can keep exploring the immediate and long-term effects of the large number of synthetic chemicals on human health, and incorporate them into our analysis to get better understanding of public health crisis and human species crisis.

\section{FUNDING STATEMENT}

The authors received no funding from any sources.

\section{CONFLICTS OF INTEREST}

No. The authors have written extensively about health optimization, personal lifestyles, and personal health. However, their works do not promote anything they own or make, such as patented drugs or owned devices. All life factors discussed in this article are freely available from nature, exist in human genes, or passed down from evolution. The authors will not gain more by doing different analyses, choosing different options, or providing different ratings for options because all options are free or available from independent sources.

\section{REFERENCES:}

(Due to a very large scope of covered materials, references are cited by examples only. The actual support references would be more than a million.)

1. Wu J, Zha P. Randomized Clinical Trial Is Biased and Invalid In Studying Chronic Diseases, Compared with Multiple Factors Optimization Trial. Preprints 2019, 2019110245. Accessed from https://www.preprints.org/manuscript/ 201911.0245/v1. DOI: http://dx.doi.org/10.2139/ssrn.3480523

2. Wu J, Zha P. Clinical Trials and Reductionist Approach Preclude Cures for Chronic Diseases Due to Flawed Presumptions. Preprints 2020, 2020090572 
(doi: 10.20944/preprints202009.0572.v1). Accessed from https://www.preprints.org/manuscript/202009.0572/v1

3. Tackling the burden of chronic diseases in the USA. Lancet. 2009;373(9659):185. Accessed at http://www.thelancet.com/journals/lancet/article/PIIS0140-6736(09)60048-9/fulltext

4. DeVol R. and Bedroussian A. An Unhealthy America: The Economic Burden of Chronic Disease. October 2007. Milken Institute Report. Page 1-35.

5. WHO, The top 10 causes of death. Accessed at https://www.who.int/ news-room/fact-sheets/detail/the-top-10-causes-of-death. Accessed on May 17, 2020.344 .

6. Wikipedia. List of incurable diseases. Accessed from https://en.wikipedia.org/wiki/List_of_incurable_diseases. Accessed on May 17, 2020.

7. Kresser C, Two Reasons Conventional Medicine Will Never Solve Chronic Disease, Accessed from https://kresserinstitute.com/two-reasons-conventional-medicine-will-never-solve-chronic-disease/

8. Green AR. Why the disease-based model of medicine fails our patients. West J Med. 2002 Mar; 176(2): 141-143.

9. Cole T. Failures of Medicine. British Medical Journal. 1875; Nov. 6; 579582.

10. Malhotra A. Why modern medicine is a major threat to public health. Thu 30 Aug 201807.13 EDT. Gardian: https://www.theguardian.com/society/ 2018/aug/30/modern-medicine-major-threat-public-health

11. Advisory Board, Precision medicine fails for up to $93 \%$ of patients. Are its proponents selling 'false hope'? September 21, 2018, Accessed from https:// www.advisory.com/daily-briefing/2018/09/21/precision-medicine

12. DeVol R. and Bedroussian A. An Unhealthy America: The Economic Burden of Chronic Disease. October 2007. Milken Institute Report. Page 1-35.

13. U.S. Health Care from a Global Perspective, 2019: Higher Spending, Worse Outcomes? Issue Briefs January 30, 2020 Accessed from https://www.commonwealthfund.org/publications/issue-briefs/2020/jan/us-health-care-global-perspective-2019

14. Wu, JQ and Zha, P. Surgery, Chemotherapy and Radiotherapy Promote Cancer Growth Speeds and Shorten Patient Lives (November 14, 2019). Available at SSRN: https://ssrn.com/abstract=3487080 DOI: 10.13140/ 
15. Wu J, Zha P. Population-Based Reductionist Measures Cannot Prevent SARS-CoV-2 Induced Global Health Crisis: A Compelling Need To Improve Personal Resistance to the Virus. Preprints 2020, 2020080503. Accessed from https://www.preprints.org/manuscript/202008.0503/v1

16. By David Robson, 6th March 2015 BBC Future. Cancer: The mysterious miracle cases inspiring doctors.

17. Boasso A, Shearer GM, Chougnet C. Immune dysregulation in human immunodeficiency virus infection: know it, fix it, prevent it? J Intern Med. 2009 January; 265(1):78-96. doi:10.1111/j.1365-2796.2008.02043.x

18. Duffin J. Medical Miracles: Doctors, Saints, and Healing in the Modern World. Oxford: 2008.

19. Rohdenburg GL. Fluctuations of the growth energy of malignant tumors in man with especial reference to spontaneous reference. Cancer Res. 1918;(3)2:193-225.

20. Everson TC, Cole WH. Spontaneous regression of cancer: preliminary report. Ann Surg. 1956;144(3):366-80.

21. Barrett R, Morash B, Roback D, et al. FISH identifies a KAT6A/CREBBP fusion caused by a cryptic insertional $t(8 ; 16)$ in a case of a spontaneously remitting congenital acute myeloid leukemia with normal karyotype. Pediatr Blood Cancer. 2017;64(8). doi: 10.1002/pbc.26450

22. D’Arena G, Guariglia R, Pietrantuono G, et al. More on spontaneous regression of chronic lymphocytic leukemia: two new cases and potential role of lamivudine in a further patient with advanced disease and hepatitis B virus infection. Leuk Lymphoma. 2014:55(8):1955-7. doi: 10.3109/10428194.2013.858151

23. Udupa K, Philip A, Rajendranath R, Sagar T, Majhi U. Spontaneous regression of primary progressive Hodgkin's lymphoma in a pediatric patient: a case report and review of literature. Hematol Oncol Stem Cell Ther. 2013;6(34):112-6. doi: 10.1016/j.hermonc.2013.06.004

23. Takahashi T, Ikejiri F, Takami S, et al. Spontaneous regression of intravascular large b-cell lymphoma and apoptosis of lymphoma cells: a case report. J Clin Exp Hematop. 2015;55(3):151-6. doi: 10.3960/jstrt.55.151 
24. Ito E, Nakano S, Otsuka $M$, et al. Spontaneous breast cancer remission: a case report. Int J Surg Case Rep. 2016;25:132-6. doi: 10.1016/ j.ijscr.2016.06.017

25. Nakamura Y, Noguchi Y, Satoh, E et al. Spontaneous remission of a non-small cell lung cancer possibly caused by anti-NY-ESO-1 immunity. Lung Cancer. 2009:65(1):119-22. doi: 10.1016/j.lungcan.2008.12.020

26. Kitai H, Sakakibara-Konishi J, Oizumi S, et al. Spontaneous regression of small cell lung cancer combined with cancer associated retinopathy. Lung Cancer. 2015;87(1):73-6. doi: 10.1016/j.lung ca.2014.10.015

27. Balzer BL, Ulbright TM. Spontaneous regression of testicular germ cell tumors: an analysis of 42 cases. Am J Surg Path. 2006;30(7):858-65.

28. Lee T, Guo Y, Vij S, Bansal R, Wong NC, Shayegan B. Case: spontaneous regression of post-radical prostatectomy prostate-specific antigen elevation without adjuvant therapy in a patient with lymph node metastasis. Can Urol Assoc J. 2017;11(7):E315-7. http://dx.doi.org/10.5489/cuaj.4324

29. Katano A, Takenaka R, Okuma K, Yamashita H, Nakagawa K. Repeated episodes of spontaneous regression/progression of cervical adenocarcinoma after adjuvant chemoradiation therapy: a case report. J Med Case Rep. 2015;9:114.

30. Parks AL, McWhirter RM, Evason K, Kelley RK. Cases of spontaneous tumor regression in hepatobiliary cancers: implications for immunotherapy? J Gastrointest Cancer. 2015;46(2):161-5. doi: 10.1007/s12029-015-9690-7

31. Chida K, Nakanishi K, Shomura H, et al. Spontaneous regression of transverse colon cancer: a case report. Surg Case Rep. 2017;3:65. doi: 10.1186/ s40792-017-0341-z

32. Pang C, Sharma D, Sankar T. Spontaneous regression of Merkel cell carcinoma: a case report and review of the literature. Int J Surg Case Rep. 2015;7C104-8. doi: 10.1016/j.ijscr.2014.11.027

33. Bonvalot S, Ternes N, Fiore M, et al. Spontaneous regression of primary abdominal wall desmoid tumors: more common than previously thought. Ann Surg Oncol. 2013;20(13);4096-102. doi: 10.1245/s10434-013-3197-x

34. Miller CV, Cook IS, Jayaramachandran R, Tyers AG. Spontaneous regression of a conjunctival malignant melanoma. Orbit. 2014;33(2);139-41. doi: 10. 3109/01676830.2013.851708. 
35. Diede SJ. Spontaneous regression of metastatic cancer: learning from neuroblastoma. Nat Rev Cancer. 2014;14(2):71-2 doi: 10.1038/nrc3656

36. Buder T, Deutsch A, Klink B, Voss-Bohme A. Model-based evaluation of spontaneous tumor regression in pilocytic astrocytoma. PLoS Comput Biol. 2015;11(12):e1004662. doi: 10.1371/journal.pcbi.1004662

37. Murphy KA, James BR, Guan Y, Torry DS, Wilber A, Griffith TS. Exploiting natural anti-tumor immunity for metastatic renal cell carcinoma. Hum Vaccin Immunother. 2015;11(7):1612-16.

38. Kucerova P, Cervinkova M. Spontaneous regression of tumour and the role of microbial infection - possibilities for cancer treatment. Anticancer Drugs. 2016;27(4):269-277.

39. Morton JJ, Morton JH. Cancer as a chronic disease. Ann Surg. 1953; (137):683.

40. Hejmadi M. for Conversation. The cancers that spontaneously DISAPPEAR: More than 1,000 cases have been recorded - but how could it happen? 08:36 EDT, 14 June 2016 | Updated: 11:59 EDT, 14 June 2016. Accessed from https://www.dailymail.co.uk/health/article-3640843/The-cancers-spontaneouslyDISAPPEAR-1-000-cases-recorded-happen.html

41. Norwood, K Girl's inoperable brain tumor disappears, doctors can't explain it. Usatoday. Published 6:08 a.m. ET Dec. 18, 2018 | Updated 7:35 a.m. ET Dec. 18, 2018.

42. Langreth R. Forbes Staff. Cancer Miracles. Feb 12, 2009, 06:20pm

43. Palagyi ZZ. Stage IV Cancer Healed! CBN.com Access from https:// www1.cbn.com/stage-iv-cancer-healed.

44. Jessy T. Immunity over inability: The spontaneous regression of cancer. J Nat Sci Biol Med. 2011 Jan-Jun; 2(1): 43-49. doi: 10.4103/0976-9668.82318: 10.4103/0976-9668.82318

45. Anand P, Kunnumakara AB, Sundaram C, et al. Cancer is a Preventable Disease that Requires Major Lifestyle Changes. Pharmaceutical Research. September 2008;25(9). DOI: 10.1007/s11095-008-9661-9.

46. Brücher B, Jamall IS. Somatic Mutation Theory - Why it's Wrong for Mo st Cancers. Cell Physiol Biochem 2016;38:1663-1680.

47. Maeda $\mathrm{H}$ and Khatami M. Analyses of repeated failures in cancer therapy for solid tumors: poor tumor-selective drug delivery, low therapeutic efficacy 
and unsustainable costs, Clin Transl Med. 2018; 7: 11. 44.

49. Davis C, Naci H, Gurpinar E, Poplavska E, Pinto A, Aggarwal A. Availability of evidence of benefits on overall survival and quality of life of cancer drugs approved by European Medicines Agency: retrospective cohort study of drug approvals 2009-13, BMJ 2017;359:j4530.

50. Sloan EK, Priceman SJ, Cox BF, et al. The sympathetic nervous system induces a metastatic switch in primary breast cancer. Cancer Research. 2010;70(18):7042-7052.

51. Lutgendorf SK, Sood AK, Anderson B, et al. Social support, psychological distress, and natural killer cell activity in ovarian cancer. Journal of Clinical Oncology. 2005;23(28):7105-7113.

52. Lutgendorf SK, DeGeest K, Dahmoush L, et al. Social isolation is associated with elevated tumor norepinephrine in ovarian carcinoma patients. Brain, Behavior, and Immunity. 2011;25(2):250-255.

53. Moreno-Smith M, Lutgendorf SK, Sood AK. Impact of stress on cancer metastasis. Future Oncology. 2010;6(12):1863-1881.

54. Cormie P, Zopf EM, Zhang X, Schmitz KH. The Impact of Exercise on Cancer Mortality, Recurrence, and Treatment-Related Adverse Effects. Epidemiologic Reviews. January 2017;39(1):71-92.

55. Holmes MD, Chen WY, Feskanich D, et al. Physical activity and survival after breast cancer diagnosis. JAMA. 2005;293(20):2479-2486.

56. Meyerhardt JA, Heseltine D, Niedzwiecki D, et al. Impact of physical activity on cancer recurrence and survival in patients with stage III colon cancer: findings from CALGB 89803. J Clin Oncol. 2006;24(22):3535-3541.

57. Des Guetz G, Uzzan B, Bouillet T, et al. Impact of physical activity on cancer-specific and overall survival of patients with colorectal cancer. Gastroenterol Res Pract. 2013;2013:340851.

58. Ibrahim EM, Al-Homaidh A. Physical activity and survival after breast cancer diagnosis: meta-analysis of published studies. Med Oncol. 2011;28(3):753-765.

59. Lahart IM, Metsios GS, Nevill AM, et al. Physical activity, risk of death and recurrence in breast cancer survivors: a systematic review and meta-analysis of epidemiological studies. Acta Oncol. 2015;54(5):635-654.

50. Friedenreich CM, Neilson HK, Farris MS, et al. Physical activity and Immune Dynamics, Wu-v102 
cancer outcomes: a precision medicine approach. Clin Cancer Res. 2016;22(19):4766-4775.

61. Li T, Wei S, Shi Y, et al. The dose-response effect of physical activity on cancer mortality: findings from 71 prospective cohort studies. Br J Sports Med. 2016;50(6):339-345.

62. Otto SJ, Korfage IJ, Polinder S et al. Association of change in physical activity and body weight with quality of life and mortality in colorectal cancer: a systematic review and meta-analysis. Support Care Cancer. 2015;23(5):12371250.

63. Schmid D, Leitzmann MF. Association between physical activity and mortality among breast cancer and colorectal cancer survivors: a systematic review and meta-analysis. Ann Oncol. 2014;25(7):1293-1311.

64. Wu W, Guo F, Ye J, et al. Pre- and post-diagnosis physical activity is associated with survival benefits of colorectal cancer patients: a systematic review and meta-analysis. Oncotarget. 2016;7(32):52095-52103.

65. Zhong S, Jiang T, Ma T, et al. Association between physical activity and mortality in breast cancer: a meta-analysis of cohort studies. Eur J Epidemiol. 2014;29(6):391-404.

66. Xu X, Hu H, Dailey AB, et al. Potential Health Impacts of Heavy Metals on HIV-Infected Population in USA PLoS One. 2013; 8(9): e74288. doi: 10.1371/journal.pone.0074288 (HIV-infected patients might be significantly more exposed to cadmium compared to non-HIV infected individuals)

67. Silverstein PS, Shah A, Gupte R, et al. Methamphetamine toxicity and its implications during HIV-1 infection J Neurovirol. 2011 October; 17(5): 401415. doi:10.1007/s13365-011-0043-4. (MA has been shown to exhibit detrimental effects on the blood-brain barrier (BBB) that have the potential to increase the probability of CNS infection by HIV, and MA induced increase in HIV-1 replication in human MDMs, and increase in co-receptor expression on dendritic cells.)

68. Talman A, Bolton S, Walson JL, et al. Interactions Between HIV/AIDS and the Environment: Toward a Syndemic Framework Am J Public Health. 2013 February; 103(2): 253-261 (HIV is a problem linked to global environment and ecosystem.)

68a. $\mathrm{Gu}$, J. et al. Multiple organ infection and the pathogenesis of SARS. J. Exp. Med. 2005;202, 415-424. (This article describes the presence of SARS-CoV 
viral particles and RNA in T cells, monocytes and macrophages, suggesting that SARS-CoV and potentially SARS-CoV-2 may drive immunopathogenesis by direct infection of immune cells).

69. WHO. Living with HIV when one partner is positive and the other is negative, 1 November 2012, Accessed from https://www.who.int/news-room/feature-stories/detail/living-with-hiv-when-onepartner-is-positive-and-the-other-is-negative

70. Anglewicz PA, Bignami-Van Assche S, Clark S, Mkandawire J. HIV Risk Among Currently Married Couples in Rural Malawi: What Do Spouses Know About Each Other? AIDS Behav. 2010 February; 14(1): 103-112. doi:10.1007/s10461-008-9497-7.

71. de Walque D. Sero-discordant couples in five African countries: Implications for prevention strategies. Population and Development Review. 2007; 33(3):501-523.10.1111/j.1728-4457.2007.00182.x

72. Alissa EM, Ferns GA. Heavy Metal Poisoning and Cardiovascular Disease. Hindawi Publishing Corporation, Journal of Toxicology. Volume 2011, Article ID 870125, 21 pages. doi:10.1155/2011/870125

73. American Heart Association. Get the Scoop on Sodium and Salt. Last Reviewed: Apr 16, 2018. Accessed from https://www.heart.org/en/healthy-living/ healthy-eating/eat-smart/sodium/sodium-and-salt

74. Yu E, Malik VS, Hu FB, Cardiovascular Disease Prevention by Diet Modification: JACC Health Promotion Series. J Am Coll Cardiol. 2018 August 21; 72(8): 914-926. doi:10.1016/j.jacc.2018.02.085.

75. Sundquist J, Li X, Johansson SE, Sundquist K. Depression as a predictor of hospitalization due to coronary heart disease. Am J Prev Med. 2005; 29: 428433.

76. Brydon L, Magid K, Steptoe A. Platelets, coronary heart disease, and stress. Brain Behav Immun. 2006;20: 113-119.

78. Booth FW, Roberts CK, Laye MJ. Lack of exercise is a major cause of chronic diseases. Compr Physiol. 2012;2:1143-1211.

79. Galán JE. Bacterial toxins and the immune system: show me the in vivo targets. J Exp Med. 2005 Feb 7; 201(3): 321-323.

79a. Domínguez-Díaz1 C, García-Orozco A, Riera-Leal A, et al. Microbiota and Its Role on Viral Evasion: Is It With Us or Against Us? Front. Cell. Infect. Mi- 
crobiol., 18 July 2019 | https://doi.org/10.3389/fcimb.2019.00256

79b. Sanjuán R. Collective infectious units in viruses. Trends Microbiol. 2017 May; 25(5): 402-412.

79c. Shirogane Y, Watanabe S, Yanagi Y. Cooperation between different variants: A unique potential for virus evolution. Virus Res. 2019 Apr 15;264:6873.

79d. Leeks A, Segredo-Otero EA, Sanjuán R, West SA. Beneficial coinfection can promote within-host viral diversity. Virus Evol. 2018;4/2.

79e. Vignuzzi M, Stone JK, Arnold JJ, et al. Quasispecies Diversity Determines Pathogenesis Through Cooperative Interactions in a Viral Population, Nature, 2006; 439:344-8.

79f. Peña J, Chen-Harris H, Allen JE, et al. Sendai virus intra-host population dynamics and host immunocompetence influence viral virulence during in vivo passage. Virus Evol. 2016 Jan; 2(1): vew008. Published online 2016 Apr 9. doi: 10.1093/ve/vew008

80. Marth E, Jelovcan S, Kleinhappl B, et al. The effect of heavy metals on the immune system at low concentrations. Int J Occup Med Environ Health. $2001 ; 14(4): 375-86$.

80a. Domingoa JL, Roviraa J, Effects of air pollutants on the transmission and severity of respiratory viral infections. Environ Res. 2020 Aug; 187: 109650. doi: 10.1016/j.envres.2020.109650 (air pollutants are associated with transmission of respiratory viruses).

81. Segerstrom SC, Miller GE. Psychological stress and the human immune system: a meta-analytic study of 30 years of inquiry. Psychol Bull. 2004 Jul;130(4):601-30.

82. McCann SM. NY Acad Sci; 1997. Neuroimmunomodulation: Molecular aspects, integrative systems, and clinical advances. https://doi.org/10.1111/ j.1749-6632.1998.tb09542.x

83. Dhabhar FS. Effects of stress on immune function: the good, the bad, and the beautiful. Immunol Res. 2014 May;58(2-3):193-210.

84. Webster Marketon JI, Glaser R. Stress hormones and immune function. Cell Immunol. 2008 Mar-Apr;252(1-2):16-26.

85. Pedersen AF, Zachariae R, Bovbjerg DH. Psychological stress and antibody response to influenza vaccination: a meta-analysis. Brain Behav Immun. 
2009 May;23(4):427-33.

86. Pedersen A, Zachariae R, Bovbjerg DH. Influence of psychological stress on upper respiratory infection-a meta-analysis of prospective studies. Psychosom Med. 2010 Oct;72(8):823-32.

87. Walburn J, Vedhara K, Hankins M, Rixon L, Weinman J. Psychological stress and wound healing in humans: a systematic review and meta-analysis. J Psychosom Res. 2009 Sep;67(3):253-71.

88. Hawryluck L, Gold WL, Robinson S, Pogorski S. Galea S, Styra R. SARS Control and Psychological Effects of Quarantine, Toronto, Canada. Emerg Infect Disv. 2004;10 (7),1206-12.

88a. Asimakos A, Toumpanakis D, Karatza $\mathrm{M}-\mathrm{H}$, et al. Immune cell response to strenuous resistive breathing: comparison with whole body exercise and the effects of antioxidants. International Journal of COPD. 2018:13:529-544. (Increased airway resistance not only induces inflammation and lung injury, but also precipitate, through oxidative stress, peripheral immune alterations.)

88b. Tseng, CT, Perrone, LA, Zhu, H, et al. Severe acute respiratory syndrome and the innate immune responses: modulation of effector cell function without productive infection. J. Immunol. 2005;174:7977-7985.

88c. Shi Y, Wang Y, Shao C, et al. COVID-19 infection: the perspectives on immune responses. Cell Death \& Differentiation. 2020;27:1451-1454.

88d. Miller AH, Ancoli-Israel S, Bower JE, et al. Neuroendocrine-immune mechanisms of behavioral comorbidities in patients with cancer. J Clin Oncol. 2008;26(6):971-82.

88e. Quan N. Immune-to-brain signaling: how important are the bloodbrain barrier-independent pathways? Mol Neurobiol. 2008; 37(2-3):142-52.

88f. Banks WA, Erickson MA. The blood-brain barrier and immune function and dysfunction. Neurobiol Dis. 2010; 37(1):26-32.

89. Evans SS, Repasky EA, and Fisher DT. Fever and the thermal regulation of immunity: the immune system feels the heat. Nat Rev Immunol. 2015 June; 15(6): 335-349. doi:10.1038/nri3843.

90. Mazzoccoli G, Vinciguerra M, Carbone A, and Relógio A. The Circadian Clock, the Immune System, and Viral Infections: The Intricate Relationship Between Biological Time and Host-Virus Interaction. Pathogens. 2020 Feb; 9(2): 83.

91. Nieman DC, Henson DA, Nehlsen-Cannarella SL, et al. Influence of Immune Dynamics, Wu-v102 
Obesity on Immune Function. Journal of the American Dietetic Association. 1999; 99: 294-9.

92. Smith AG, Sheridan PA, Harp JB, et al. Diet-Induced Obese Mice have Increased Mortality and Altered Immune Responses when Infected with Influenza Virus. Journal of Nutrition. 2007;37:1236-43.

93. Ritz BW, Gardner EM. Malnutrition and Energy Restriction Differentially Affect Viral Immunity, Journal of Nutrition. 2006;136:1141-4.

93a. Levander OA. Nutrition and Newly Emerging Viral Diseases: An Overview, Journal of Nutrition. 1997;127: 948S-50S.

93b. Beck MA. Selenium and Vitamin E Status: Impact on Viral Pathogenicity. Journal of Nutrition. 2007;137: 1338-40.

93c. Nelson HK, Shi Q, Van Dael P, et al. Host Nutritional Selenium Status as a Driving Force for Influenza Virus Mutations. The FASEB Journal. 2001; 15: 1846-8.

93d. Barnett JB, Hamer DH, Meydani SN. Zinc: a new risk factor for pneumonia in the elderly. Nutr Rev. 2010 Jan; 68(1): 30-37.

94. Loh L, Wang Z, Sant S, et al. Human mucosal-associated invariant T cells contribute to antiviral influenza immunity via IL-18-dependent activation. Proc Natl Acad Sci USA 2016; 113: 10133-10138.

95. Yoo J-K, Kim TS, Hufford MM, Braciale TJ. Viral infection of the lung: Host response and sequelae. J Allergy Clin Immunol. 2013 December; 132(6):128.

96. Handfield C, Kwock J, and MacLeod AS. Innate Antiviral Immunity in the Skin. Trends Immunol. 2018 April; 39(4): 328-340.

97. Hu D, Wan L, Chen M, Caudle Y, LeSage G, Li Q, Yin D. Essential role of IL-10/STAT3 in chronic stress-induced immune suppression. Brain Behav Immun. 2014 Feb; 36:118-127.

98. Schakel L, Veldhuijzen DS, Crompvoets PI, et al. Effectiveness of Stress-Reducing Interventions on the Response to Challenges to the Immune System: A Meta-Analytic Review. Published online 2019 Aug 6. doi: 10.1159/000501645: 10.1159/000501645

99. Karlsson EA, Beck MA. Diet-Induced Obesity Impairs The T Cell Memory Response to Influenza Virus Infection, The FASEB Journal, 2009;23: 110-3. 
100. Karlsson EA, Sheridan PA, Beck MA. Diet-Induced Obesity Impairs the T Cell Memory Response to Influenza Virus Infection, The Journal of Immunology, 2010;184:3127-33.

101. Mito N, Hosoda T, Kato C, et al. Change of Cytokine Balance in DietInduced Obese Mice, Metabolism, 2000;49:1295-300.

101. Rathee P, Chaudhary H, Rathee S, et al. Immunosuppressants: A Review THE PHARMA INNOVATION - JOURNAL Vol. 1 No. 122012.

102. Winans B, Humble MC, Lawrence BP. Environmental toxicants and the developing immune system: a missing link in the global battle against infectious disease? Reprod Toxicol. 2011 April;31(3): 327-336.

doi:10.1016/j.reprotox.2010.09.004.

103. Naidenko OV, Andrews DQ, Temkin AM. Investigating Molecular Mechanisms of Immunotoxicity and the Utility of ToxCast for Immunotoxicity Screening of Chemicals Added to Food. Int. J. Environ. Res. Public Health 2021, 18, 3332. https://doi.org/10.3390/ijerph18073332

104 Search the database using "Immune suppression" https://www.healthandenvironment.org/our-work/toxicant-and-disease-database/? showdisease $=693$

105. Rosenthal KS (2017) Dealing with Garbage is the Immune System's Main Job. MOJ Immunol 5(6): 00174. DOI: 10.15406/moji.2017.05.00174

106. Neupane AS, Willson M, Chojnacki AK, et al. Patrolling Alveolar Macrophages Conceal Bacteria from the Immune System to Maintain Homeostasis. Cell. 2020;183(1):110-125. (AMs crawling in and between alveoli using the pores of Kohn. These macrophages sensed, chemotaxed, and, with high efficiency, phagocytosed inhaled bacterial pathogens such as P. aeruginosa and S. aureus, cloaking the bacteria from neutrophils. Impairing AM chemotaxis toward bacteria induced superfluous neutrophil recruitment, leading to inappropriate inflammation and injury.)

107. Rodero MP, Poupel L, Loyher P-L, et al. Immune surveillance of the lung by migrating tissue monocytes. eLife 2015;4:e07847. DOI: 10.7554/ eLife.07847

108. Baumgarth N, Herman OC, Jager GC, et al. Innate and acquired humoral immunities to influenza virus are mediated by distinct arms of the immune system. Proc Natl Acad Sci USA (1999) 96:2250-5. doi:10.1073/pnas.96.5.2250

109. Gu, J. et al. Multiple organ infection and the pathogenesis of SARS. J. 
Exp. Med. 2005;202, 415-424. This article describes the presence of SARS-CoV viral particles and RNA in T cells, monocytes and macrophages, suggesting that SARS-CoV and potentially SARS-CoV-2 may drive immunopathogenesis by direct infection of immune cells.

110. Huang YC, Feng ZP. The good and bad of microglia/macrophages: new hope in stroke therapeutics. Acta Pharmacol Sin 2013;34(1): 6-7.

111. Aras S and Zaidi MR, TAMeless traitors: macrophages in cancer progression and metastasis. British Journal of Cancer. (2017) 117, 1583-1591.

112. Noy R and Pollard JW. Tumor-associated macrophages: from mechanisms to therapy. Immunity. 2014 July 17; 41(1): 49-61.

113. Bortz WMT, Bortz WM 2nd. How fast do we age? Exercise performance over time as a biomarker. J Gerontol A Biol Sci Med Sci. 1996; 51:M2235 .

114. Goldspink DF. Ageing and activity: Their effects on the functional reserve capacities of the heart and vascular smooth and skeletal muscles. Ergonomics. 2005;48:1334-51.

115. Sehl ME, Yates FE. Kinetics of human aging: I. Rates of senescence between ages 30 and 70 years in healthy people. J Gerontol A Biol Sci Med Sci. 2001; 56:B198-208.

116. Cupit-Link MC, Kirkland JL, Ness KK, et al. Biology of premature ageing in survivors of cancer. ESMO Open. 2017 December 18.

117. López-Otín C, Blasco MA, Partridge L, et al. The hallmarks of aging. Cell 2013;153:1194-217.

117a. Friedman GD, Ury HK. Initial screening for carcinogenicity of commonly used drugs. JNCI. 1980;65:723-733.

117b. Friedman GD, Ury HK. Screening for possible drug carcinogenicity: second report of findings. JNCI. 1983;71:1165-1175.

117c. Friedman GD, Udaltsova N, Chan J, etc. Screening pharmaceuticals for possible carcinogenic effects: initial positive results for drugs not previously screened: initial positive results for drugs not previously screened. Cancer Causes Control. 2009 Dec; 20(10): 1821-1835. doi: 10.1007/s10552-009-9375-2

117d. Amerio A, Gálvez JF, Odone A, et al. Carcinogenicity of psychotropic drugs: A systematic review of US Food and Drug Administration-required preclinical in vivo studies. Australian \& New Zealand Journal of Psychiatry. 
2015;49(8) 686-696.

118. Wu J, Zha P. Proactive Body Temperature Management Protocol and Lifestyle Interventions as Predictable Cures for COVID-19 Disease: Curative Protocols Discovered from a Century of Medical Discoveries. https://osf.io/pcfna, DOI: $10.31219 /$ osf.io/pcfna

119. Eccles R. An Explanation for the Seasonality of Acute Upper Respiratory Tract Viral Infections. Acta Otolaryngol 2002; 122:183-191.

120. Lowen AC, Steel J. Roles of Humidity and Temperature in Shaping Influenza Seasonality. Journal of Virology. July 2014; 88:14,7692-7695.

121. Tzampoglou P, Loukidis Dimitrios. Investigation of the Importance of Climatic Factors in COVID-19 Worldwide Intensity. Int. J. Environ. Res. Public Health 2020, 17, 7730.

122. Nieman DC, Wentz LM. The compelling link between physical activity and the body's defense system. Journal of Sport and Health Science 8 (2019) 201-217

123. Pedersen BK, Hoffman-Goetz L. Exercise and the immune system: regulation integration and adaption. Physiol Rev. 2000;80(3):1055-1081. doi: 10.1152/physrev.2000.80.3.1055.

124. Leandro CG, Castro RM, Nascimento E, Pithon-Curi TC, Curi R. Adaptative mechanisms of the immune system in response to physical training. Rev Bras Med Esporte. 2007;13(5):343-348. doi: 10.1590/S151786922007000500012.

125. Mackinnon LT. Changes in some cellular immune parameters following exercise training. Med Sci Sports Exerc 1986;18:596-7.

126. Mackinnon LT, Chick TW, van As A, Tomasi TB. The effect of exercise on secretory and natural immunity. Adv Exp Med Biol 1987;216A:869-76.

127. Hoffman-Goetz L, Keir R, Thorne R, Houston ME, Young C. Chronic exercise stress in mice depresses splenic $\mathrm{T}$ lymphocyte mitogenesis in vitro. Clin Exp Immunol 1986;66:551-7.

128. Hoffman-Goetz L, Thorne RJ, Houston ME. Splenic immune responses following treadmill exercise in mice. Can J Physiol Pharmacol 1988;66:1415-9.

129. Pedersen BK, Tvede N, Hansen FR, Andersen V, Bendix T, Bendixen G, et al. Modulation of natural killer cell activity in peripheral blood by physical exercise. Scand J Immunol 1988;27:673-8. 
130. Tvede N, Pedersen BK, Hansen FR, Bendix T, Christensen LD, Galbo $\mathrm{H}$, et al. Effect of physical exercise on blood mononuclear cell subpopulations and in vitro proliferative responses. Scand J Immunol 1989;29:383-9.

131. Nieman DC, Tan SA, Lee JW, Berk LS. Complement and immunoglobulin levels in athletes and sedentary controls. Int J Sports Med 1989;10:124-8.

132. Nieman DC, Johanssen LM, Lee JW. Infectious episodes in runners before and after a roadrace. J Sports Med Phys Fitness 1989;29:289-96.

133. Nieman DC, Johanssen LM, Lee JW, Arabatzis K. Infectious episodes in runners before and after the Los Angeles Marathon. J Sports Med Phys Fitness 1990;30:316-28.

134. Cannon JG, Kluger MJ. Endogenous pyrogen activity in human plasma after exercise. Science 1983;220:617-9.

135. Adams GR, Zaldivar FP, Nance DM, Kodesh E, Radom-Aizik S, Cooper DM. Exercise and leukocyte interchange among central circulation, lung, spleen, and muscle. Brain Behav Immun 2011;25:658-66.

136. Bigley AB, Rezvani K, Chew C, Sekine T, Pistillo M, Crucian B, et al. Acute exercise preferentially redeploys NK-cells with a highly-differentiated phenotype and augments cytotoxicity against lymphoma and multiple myeloma target cells. Brain Behav Immun 2014;39:160-71.

137. Gupta P, Bigley AB, Markofski M, Laughlin M, LaVoy EC. Autologous serum collected $1 \mathrm{~h}$ post-exercise enhances natural killer cell cytotoxicity. Brain Behav Immun 2018;71:81-92.

138. Nieman DC, Henson DA, Austin MD, Brown VA. Immune response to a 30-minute walk. Med Sci Sports Exerc 2005;37:57-62.

139. Viana JL, Kosmadakis GC, Watson EL, Bevington A, Feehally J, Bishop $\mathrm{NC}$, et al. Evidence for anti-inflammatory effects of exercise in CKD. J Am Soc Nephrol 2014;25:2121-30.

140. Evans ES, Hackney AC, McMurray RG, Randell SH, Muss HB, Deal $\mathrm{AM}$, et al. Impact of acute intermittent exercise on natural killer cells in breast cancer survivors. Integr Cancer Ther 2015;14:436-45.

141. Ferrandi PJ, Fico BG, Whitehurst M, Zourdos MC, Bao F, Dodge KM, et al. Acute high-intensity interval exercise induces comparable levels of circulating cell-free DNA and interleukin-6 in obese and normal-weight individuals. Life Sci 2018;202:161-6. 
142. Simpson RJ, Kunz H, Agha N, Graff R. Exercise and the regulation of immune functions. Prog Mol Biol Transl Sci 2015;135:355-80.

143. Simpson RJ, Bigley AB, Agha N, Hanley PJ, Bollard CM. Mobilizing immune cells with exercise for cancer immunotherapy. Exerc Sport Sci Rev 2017;45:163-72.

144. LaVoy EC, Bollard CM, Hanley PJ, Blaney JW, O’Connor DP, Bosch JA, et al. A single bout of dynamic exercise enhances the expansion of MAGE-A4 and PRAME-specific cytotoxic T-cells from healthy adults. Exerc Immunol Rev 2015;21:144-53.

145. Turner JE, Spielmann G, Wadley AJ, Aldred S, Simpson RJ, Campbell JP. Exercise-induced B cell mobilization: preliminary evidence for an influx of immature cells into the bloodstream. Physiol Behav 2016;164:376-82.

146. Campbell JP, Riddell NE, Burns VE, Turner M, van Zanten JJ, Drayson MT, et al. Acute exercise mobilizes CD8+ T lymphocytes exhibiting an effectormemory phenotype. Brain Behav Immun 2009;23:767-75.

147. M€uller L, Pawelec G. Aging and immunity-impact of behavioral intervention. Brain Behav Immun 2014;39:8-22.

148. Pascoe AR, Fiatarone Singh MA, Edwards KM. The effects of exercise on vaccination responses: a review of chronic and acute exercise interventions in humans. Brain Behav Immun 2014;39:33-41.

149. Simpson RJ, Lowder TW, Spielmann G, Bigley AB, LaVoy EC, Kunz H. Exercise and the aging immune system. Ageing Res Rev 2012;11:404-20.

150. Nieman DC, Gillitt ND, Sha W, Esposito D, Ramamoorthy S. Metabolic recovery from heavy exertion following banana compared to sugar beverage or water only ingestion: a randomized, crossover trial. PLoS One 2018;13:e0194843. doi:10.1371/journal.pone.0194843.

151. Simpson RJ, Lowder TW, Spielmann G, Bigley AB, LaVoy EC, Kunz H. Exercise and the aging immune system. Ageing Res Rev 2012;11:404-20.

152. Nieman DC, Henson DA. Role of endurance exercise in immune senescence. Med Sci Sports Exerc 1994;26:172-81.

153. Simpson RJ, Kunz H, Agha N, Graff R. Exercise and the regulation of immune functions. Prog Mol Biol Transl Sci 2015;135:355-80.

154. Walter Bradford Cannon (1915). Bodily Changes in Pain, Hunger, Fear and Rage: An Account of Recent Researches into the Function of Emotional Ex- 
citement. Appleton-Century-Crofts.

155. Adrenaline, Cortisol, Norepinephrine: The Three Major Stress Hormones, Explained". Hufflington Post. April 19, 2014. Retrieved July 16 August 2021.

156. Kwon, Diana. "Fight or Flight May Be in Our Bones". Scientific American. Retrieved 2020-06-22.

157. Stanford University Medical Center. How stress can boost immune system. ScienceDaily. ScienceDaily, 21 June 2012. <www.sciencedaily.com/releases/2012/06/120621223525.htm>

158. Aimo A, Di Paolo M, Castiglione V, et al. Scared to Death: Emotional Stress Causing Fatal Myocardial Infarction With Nonobstructed Coronary Arteries in Women Case Report: Clinical Case Series. J Am Coll Cardiol Case Rep. 2020 Dec, 2 (15) 2400-2403.

159. Boscarino, J. A., \& Chang, J. Higher abnormal leukocyte and lymphocyte counts 20 years after exposure to severe stress: Research and clinical implications. Psychosomatic Medicine, 1999;61(3),378-386. https://doi.org/ 10.1097/00006842-199905000-00019

160. Russ TC. Association between psychological distress and mortality: individual participant pooled analysis of 10 prospective cohort studies. BMJ 2012;345:e4933 doi: https://doi.org/10.1136/bmj.e4933 (Published 31 July 2012)

160A. Cannon WB “VOODOO” Death. Am J Public Health. 2002 October; 92(10): 1593-1596.

160B. Liao Y-T, Wang S-M, Wang J-R. Norepinephrine and Epinephrine Enhanced the Infectivity of Enterovirus 71. 2015 Aug 7;10(8):e0135154. doi: 10.1371/journal.pone.0135154. eCollection 2015.

161. Catania RA, Chaudry IH. Immunological consequences of trauma and shock. Ann Acad Med Singap. 1999 Jan;28(1):120-32.

162. Anant JK, Inchulkar SR, Bhagat S. A REVIEW ARTICLE ON FOOD POISONING, wjpls, 2018, Vol. 4, Issue 9, 94-99.

163. Mead PS, Slutsker L, Dietz V, et al. Food-Related Illness and Death in the United States. Emerg Infect Dis. 1999;5(5):607-625.

https://doi.org/10.3201/eid0505.990502 
164. Kudo E. Song E, Yockey LJ, Low ambient humidity impairs barrier function and innate resistance against influenza infection. Proc Natl Acad Sci U S A. 2019 May 28; 116(22): 10905-10910. doi: 10.1073/pnas.1902840116

165. Maltzman JS, Haase VH. Low oxygen stimulates the immune system. Kidney Int. 2008 Apr; 73(7): 797-799. doi: 10.1038/ki.2008.15

166. Naruse Y. Mechanical vibration model for chromosomes in metaphase of mitosis and possible application to the interruption of cell division. Biosystems Jun-Jul 2002;66(1-2):55-63. doi: 10.1016/s0303-2647(02)00033-3.

167. Yeung PK, Wong JT. Inhibition of cell proliferation by mechanical agitation involves transient cell cycle arrest at G1 phase in dinoflagellates. Protoplasma. 2003 Mar;220(3-4):173-8.

167a. Hussain S, Tom Gallagher. SARS-Coronavirus Protein 6 Conformations Required to Impede Protein Import into the Nucleus. Virus Res. Virus Res. 2010 Nov; 153(2): 299-304.

168. Thorp EB, Boscarino JA, Logan HL, Goletz JT, Gallagher TM. Palmitoylations on murine coronavirus spike proteins are essential for virion assembly and infectivity. J Virol. 2006 Feb;80(3):1280-9.

168. Wu J, Zha P. Lung Damage Mechanisms For COVID-19 and Other Lung Infections, and Driving Force in Leukecyte Recruitment and Migration. Preprints 2020, 2020090209. Accessed from https://www.preprints.org/manuscript/ 202009.0209/v1. http://dx.doi.org/10.2139/ssrn.3689090

169. Cooper JS, Phuyal P, Shah N. Oxygen Toxicity. [Updated 2021 Jul 18]. In: StatPearls [Internet]. Treasure Island (FL): StatPearls Publishing; 2021 Jan-. Available from: https://www.ncbi.nlm.nih.gov/books/NBK430743/

170. Keusch GT. The History of Nutrition: Malnutrition, Infection and Immunity, Journal of Nutrition. 2003;133:336S-40S.

171. Ritz BW, Gardner EM. Malnutrition and Energy Restriction Differentially Affect Viral Immunity, Journal of Nutrition. 2006;136:1141-4.

172. Besedovsky L, Lange T, Born J. Sleep and immune function. Pflugers Arch. 2012; 463(1): 121-137. doi: 10.1007/s00424-011-1044-0

173. Besedovsky L, Lange T, Haack M. The Sleep-Immune Crosstalk in Health and Disease. Physiol Rev. 2019 Jul 1; 99(3): 1325-1380. doi: 10.1152/ physrev.00010.2018

174. Haspel JA, Anafi R, Brown MK, et al. Perfect timing: circadian Immune Dynamics, Wu-v102 
rhythms, sleep, and immunity - an NIH workshop summary. JCI Insight. 2020 Jan 16; 5(1): e131487.

175. Adler L. Is it Possible to Get Too Much Sleep? Updated March 12, 2021. accessed from https://www.sleep.org/is-it-possible-to-get-too-much-sleep/

176. Takahashi K. Effects of physical exhaustion on immune systems. Hokkaido Igaku Zasshi. 1998 Jan;73(1):61-71 [article in Japanese].

177. University of Cambridge. Too exhausted to fight, immune system may harm the body they are supposed to protect. Science News. Science Daily. https://www.sciencedaily.com/releases/2015/06/150629110803.htm

178. The Recovery Village. How Drinking Impacts Your Immune System: Alcohol has a variety of effects on the immune system and can make people more susceptible to infections and other health conditions, including COVID-19. https://www.therecoveryvillage.com/alcohol-abuse/related-topics/alcohol-impactsimmune-system/

179. Sarkar D, Jung MK, Wang HJ. Alcohol and the Immune System. Alcohol Research: Current Reviews 37(2): 153-155

180. Friedman H, Pross S \& Klein TW. Addictive drugs and their relationship with infectious diseases (MINIREVIEW). FEMS Immunology \& Medical Microbiology, August 2006; 47(3):330-342, https://doi.org/10.1111/j.1574-695X.2006.00097.x

181. Enevoldson TP. Recreational drugs and their neurological consequences. http://dx.doi.org/10.1136/jnnp.2004.045732

182. Dike ON, Ekwebelem O, Ofielu E, et al. Long Term Immunologic Consequences of Illicit Drug Abuse. J Alcohol Drug Depend SubstAbus 2020; 6:022.

183. Mukherjee S, Mukherjee U. A Comprehensive Review of Immunosuppression Used for Liver Transplantation. J Transplant. 2009; 2009: 701464 .

184. Schoot TS, Kerckhoffs APM, Hilbrands LB, van Marum RJ. Immunosuppressive Drugs and COVID-19: A Review. 2020;Front. Pharmacol. 11:1333. doi: 10.3389/fphar.2020.01333

185. Zdanowicz MM. The Pharmacology of Immunosuppression. Am J Pharm Educ. 2009 Dec 17; 73(8):144. doi: 10.5688/aj7308144 
186. Immunosuppressive Agents (Accession Number: DBCAT000047) https://go.drugbank.com/categories/DBCAT000047

187. Wu J, Zha P. A Multi-Factor Model for Estimating Relative Lifespans and Extending Health Spans. Accessed from https://papers.ssrn.com/sol3/papers.cfm?abstract_id=3502432

188. How long does it take prednisone to get out of your system? https://www.drugs.com/medical-answers/prednisone-how-long-does-it-takepredesone-to-get-372449/

189. Biological half-life, wikipedia, accessed from https:// en.wikipedia.org/wiki/Biological_half-life

189a. Ahonen J, Olkkola KT, Hynynen M, et al. Comparison of alfentanil, fentanyl and sufentanil for total intravenous anaesthesia with propofol in patients undergoing coronary artery bypass surgery. Br J Anaesth. 2000;85:533-40.

189b. Greco M, Landoni G, Biondi-Zoccai G, at al. Remifentanil in cardiac surgery: A meta-analysis of randomized controlled trials. J Cardiothorac Vasc Anesth. 2012;26:110-6.

189c. Texas HHS, ONSET, PEAK AND DURATION OF COMMON PAIN MEDICATIONS. Accessed from https://www.hhs.texas.gov/sites/default/files/documents/doing-business-withhhs/provider-portal/QMP/PainMedicationTable.pdf; Clinical Pharmacology, www.clinicalpharmacology.com; Drugs.com, http://www.drugs.com/professionals.html

190. Schakel L, Veldhuijzen DS, Crompvoets PI, et al. Effectiveness of Stress-Reducing Interventions on the Response to Challenges to the Immune System: A Meta-Analytic Review. Published online 2019 Aug 6. doi: 10.1159/000501645: 10.1159/000501645

191. Cinatl J, Morgenstern B, Bauer G, Chandra P, Rabenau H, Doerr HW. Glycyrrhizin, an active component of liquorice roots, and replication of SARSassociated coronavirus. Lancet 2003a;361:2045-6.

192. Jang WM, Cho S, Jang DH, et al. Preventive Behavioral Responses to the 2015 Middle East Respiratory Syndrome Coronavirus Outbreak in Korea. Int J Environ Res Public Health. 2019 Jun; 16(12): 2161.

193. Coley WB. The treatment of malignant tumors by repeated inoculations of erysipelas, with a report of ten original cases. Am J Med Sci. 1893;105:487-511. 
194. Coley WB. Contribution to the knowledge of sarcoma. Ann Surg. 1891;14:199-220.

195. Coley WB. Treatment of inoperable malignant tumors with toxins of erysipelas and the bacillus prodigiosus. Trans Am Surg Assn. 1894;12:183-212.

196. Richardson MA, Ramirez T, Russell NC, Moye LA. Coley toxins immunotherapy: A retrospective review. Altern Ther Health med. 1999;5:42-7.

197. Kox M, van Eijk LT, Zwaag J, et. al. Voluntary activation of the sympathetic nervous system and attenuation of the innate immune response in humans. PNAS May 20, 2014;111(20):7379-7384 (10 days meditation can reduce flu-like symptoms in the experiment. The study demonstrates that, through practicing [meditation] techniques learned in a short-term training program, the sympathetic nervous system and immune system can indeed be voluntarily influenced. Healthy volunteers practicing the learned techniques exhibited profound increases in the release of epinephrine, which in turn led to increased production of anti-inflammatory mediators and subsequent dampening of the proinflammatory cytokine response elicited by intravenous administration of bacterial endotoxin).

198. Wang H, Yuan X, Sun Y, Mao X, Meng C, Tan L, Song C, Qiu X, Ding C, Liao Y. Infectious bronchitis virus entry mainly depends on clathrin mediated endocytosis and requires classical endosomal/lysosomal system. Virology. 2019 Feb;528:118-136.

199. Wu J, Zha P. The Central Nervous System's Adaptive Changes Make Chronic Diseases Incurable. Preprints 2019, 2019110287. DOI: http:// dx.doi.org/10.2139/ssrn.3480562

200. Wu J. Essential Measures for Ending COVID-19 and Other Pandemics: Congress Should Establish True Health Science. https://osf.io/z4jfe, https:// www.researchgate.net/publication/348818240.

201. Huang C, Wang Y, Li X. et al. Clinical features of patients infected with 2019 novel coronavirus in Wuhan, China. Lancet 2020; 395: 497-506.

201a. Wolff D, Nee S, Hickey NS, Marschollek M. Risk factors for Covid-19 severity and fatality: a structured literature review. Infection. 2021; 49(1): 15-28. doi: 10.1007/s15010-020-01509-1.

202. Wu J, Ping Z. Public Health Intervention Framework for Reviving Economy amid the COVID-19 Pandemic (2): Use of Personalized Mitigation Measures Beyond the Epidemiological Model Limits. Preprints 2020, 2020050049. 
Accessed from https://www.preprints.org/manuscript/202005.0049/v1

203. Wu J, Zha P. Preventive, Mitigating and Treatment Strategies for Containing or Ending the COVID-19 Pandemic. Preprints 2020, 2020020450. Accessed from https://www.preprints.org/manuscript/202002.0450/v2

203a. Wu J, Zha P. Lung Damage Mechanisms For COVID-19 and Other Lung Infections, and Driving Force in Leukecyte Recruitment and Migration. Preprints 2020, 2020090209. Accessed from https://www.preprints.org/manuscript/ 202009.0209/v1. http://dx.doi.org/10.2139/ssrn.3689090

204. Qureshi F, Alam J, Khan MA, Sheraz G. Effect Of Examination Stress On Blood Cell Parameters Of Students In A Pakistani Medical College Accessed from https://ayubmed.edu.pk/JAMC/PAST/14-1/Faiyaz.htm

205. Farber DL. Tissues, not blood, are where immune cells act. Nature. 27 May 2021;(593)506-509.

206. Szakal A.K, Gieringer RL, Kosco MH, Tew JG. Isolated follicular dendritic cells: cytochemical antigen localization, Nomarski, SEM, and TEM morphology. J Immunol. 1985 Mar;134(3):1349-59.

207. George, EL. Does a high WBC count signal infection? EYE ON DIAGNOSTICS. Nursing2005: January 2005;35(1)20-21.

208. Herber TB. Stress and the immune system. World Health $\bullet$ MarchApril 1994:47(2) 4-5.

209. Russo MA, Santarelli DM, O'Rourke D. The physiological effects of slow breathing in the healthy human. Breathe 2017; 13:298-309.

210. Relaxation techniques: Breath control helps quell errant stress response - Harvard Health Harvard Health Publishing. Jul 6, 2020. Accessed from https://www.health.harvard.edu/mind-and-mood/relaxation-techniques-breathcontrol-helps-quell-errant-stress-response

211. Nuckowska MK, Gruszecki M, Kot J, et al. Impact of slow breathing on the blood pressure and subarachnoid space width oscillations in humans Scientific Reports 2019;9:6232 (Drop in cardiac component of BP amplitude evoked by slow-breathing may be perceived as a cardiovascular protective mechanism to avoid target organ damage. Further studies are warranted to assess long-term effects of slow breathing.)

212. Asimakos A, Toumpanakis D, Karatza $\mathrm{M}-\mathrm{H}$, et al. Immune cell response to strenuous resistive breathing: comparison with whole body exercise 
and the effects of antioxidants. International Journal of COPD. 2018:13:529-544. (Increased airway resistance not only induces inflammation and lung injury, but also precipitate, through oxidative stress, peripheral immune alterations.)

213. New Qigong Treatments Vol. 1. People Hygiene Publisher (A leading government publisher) Editors: Binfu Tao, Werhe Yang. 1982. Old Book No: 14048.4013. p170-200 (several articles show the treatment effects of Qigong exercise on challenging lung diseases).

214. New Qigong Treatments Vol. 2. People Hygiene Publisher (A leading government publisher). Editors: Binfu Tao, Werhe Yang. 1982. Old Book No:14048.4178. p229-272 (several comprehensive studies show how Qigong exercise affects human physiology).

215. Smith JC, Sausville EL, Girish V, et al. Cigarette Smoke Exposure and Inflammatory Signaling Increase the Expression of the SARS-CoV-2 Receptor ACE2 in th e Respiratory Tract. Developmental Cell June 8, 2020;53, 514-529.

216. Kolar P, Neuwirth J, Sanda J, et al. Analysis of diaphragm movement during tidal breathing and during its activation while breath holding using MRI synchronized with spirometry. Physiol Res 2009; 58:383-392.

217. Morgan N, Irwin MR, Chung M, Wang C. The Effects of Mind-Body Therapies on the Immune System: Meta-Analysis. PLoS ONE 2014;9(7): e100903.doi:10.1371/journal.pone.010090

218. Raj RS, Bonney EA, Phillippe, M. Influenza, Immune System, and Pregnancy. Reprod Sci. 2014 Dec; 21(12): 1434-1451. doi: 10.1177/1933719114537720

219. van der Sluijs KF, van Elden LJ, Nijhuis M, et al. IL-10 is an important mediator of the enhanced susceptibility to pneumococcal pneumonia after influenza infection. J Immunol. 2004;172 (12):7603-7609.

220. WHO Solidarity trial consortium, Hongchao Pan, Richard Peto et al, Repurposed antiviral drugs for COVID-19 -interim WHO SOLIDARITY trial results. MeddRxiv Preprint. doi: https://doi.org/10.1101/2020.10.15.20209817 (These Remdesivir, Hydroxychloroquine, Lopinavir and Interferon regimens appeared to have little or no effect on hospitalized COVID-19, as indicated by overall mortality, initiation of ventilation and duration of hospital stay.)

221. McDonald J. Vaccines Remain Largely Effective Against Delta Variant, Counter to Claims From Fox News Guest. SciCheck's COVID-19/Vaccination Project. Assessed from https://www.factcheck.org/2021/07/vaccines-remainlargely-effective-against-delta-variant-counter-to-claims-from-fox-news-guest/ 
222. Health ministry confirms detection of new mutation of Delta variant in Nepal. COVID-19 By THT Online. Published: 03:08 pm Jun 21, 2021. https://thehimalayantimes.com/covid-19/health-ministry-confirms-detection-of-new-mutation-of-delta-variant-in-nepal

223. Trovato L, Naro F, D’Aiuto F, Moren F. Promoting Tissue Repair by Micrograft Stem Cells Delivery. Hindawi Stem Cells International. Volume 2020, Article ID 2195318, 2 pages. https://doi.org/10.1155/2020/2195318

224. DiMarino AM, Caplan A, and Bonfield TL. Mesenchymal stem cells in tissue repair. Front. Immunol., 04 September 2013 https://doi.org/10.3389/ fimmu.2013.00201

225. Landi H. Medicare Actuaries: U.S. Healthcare Spending Will Rise to \$5.548 Trillion and 19.9 Percent of GDP in 2025. Feb 15th, 2017. Accessed from https://www.hcinnovationgroup.com/policy-value-based-care/article/13028126/ medicare-actuaries-us-healthcare-spending-will-rise-to-5548-trillion-and-199-percent-of-gdp-in-2025 
FIG. 1

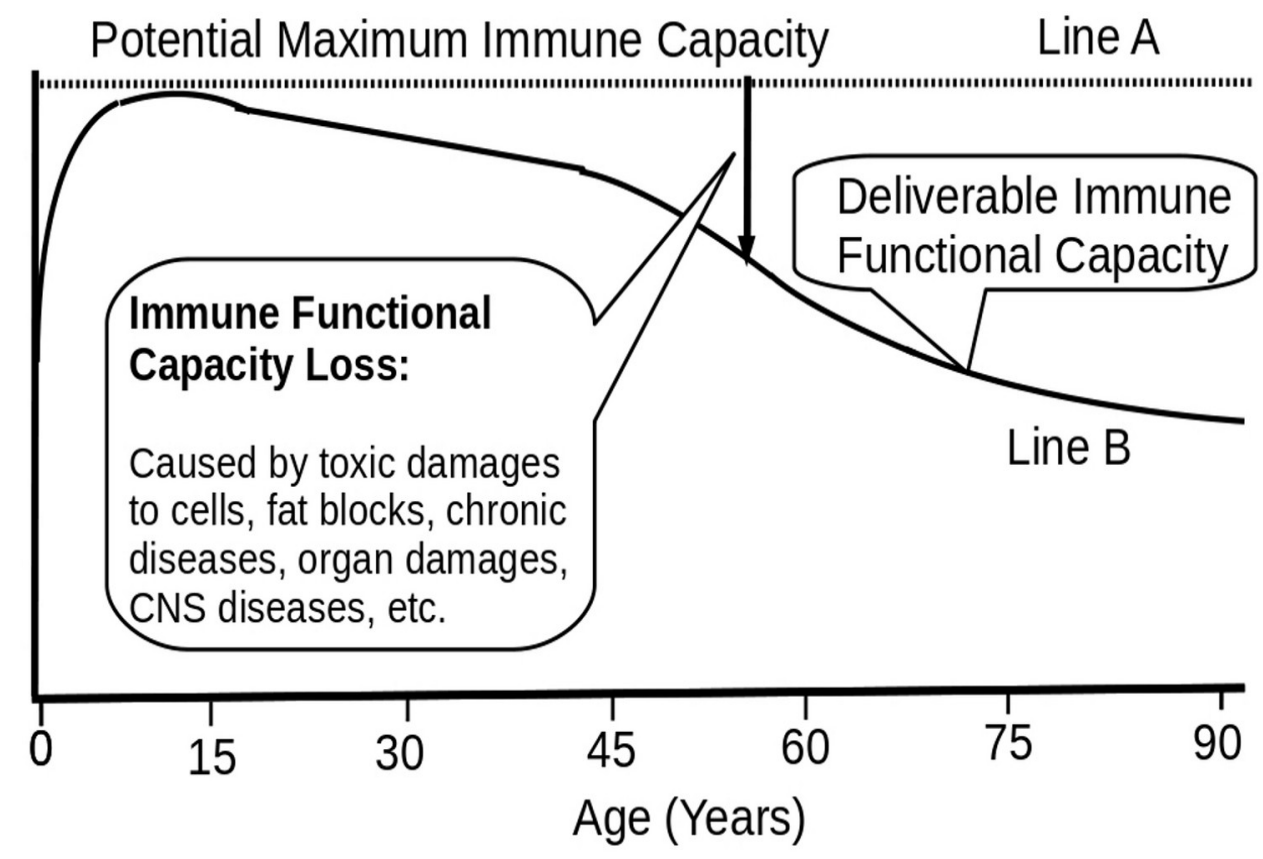

FIG. 1. Immune Functional Capacity Loss During the Lifetime of A Person. The loss of immune functional capacities are caused by changes in cells and is of permanent nature. 
FIG. 2

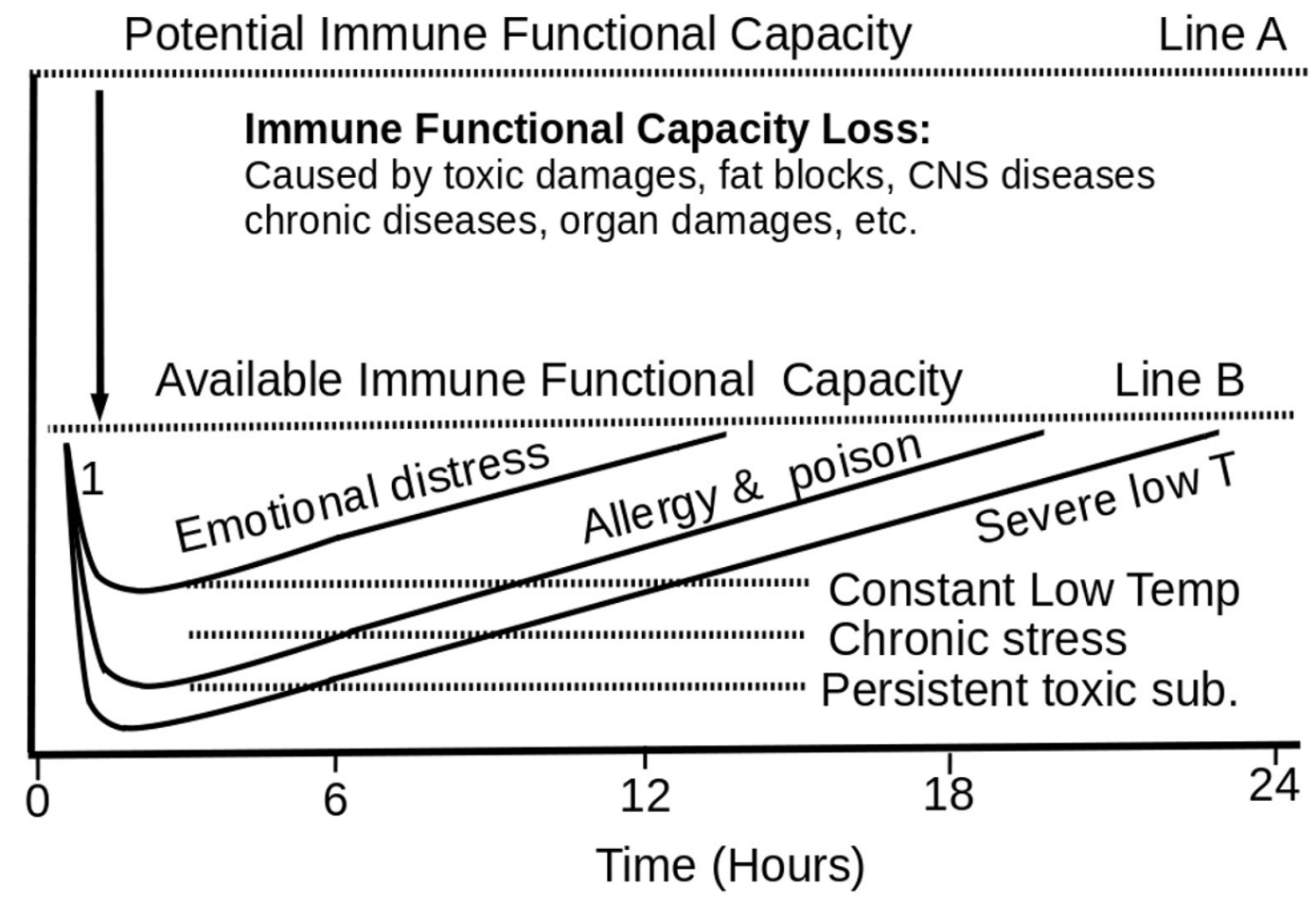

FIG. 2. Strong Immune Suppressive Effects of Several Exemplar Factors on the Current Immune Functional Capacities in A Short Time Period (24 hours). Each of those effects can have strong immediate suppressive effects and then the current capacities quickly recover. Shown are the effects of severe emotional distress, allergies and poisoning, and exposure to low temperature. There are a large number of other factors that can immediately depress the current immune functional capacities in short times. 
FIG. 3

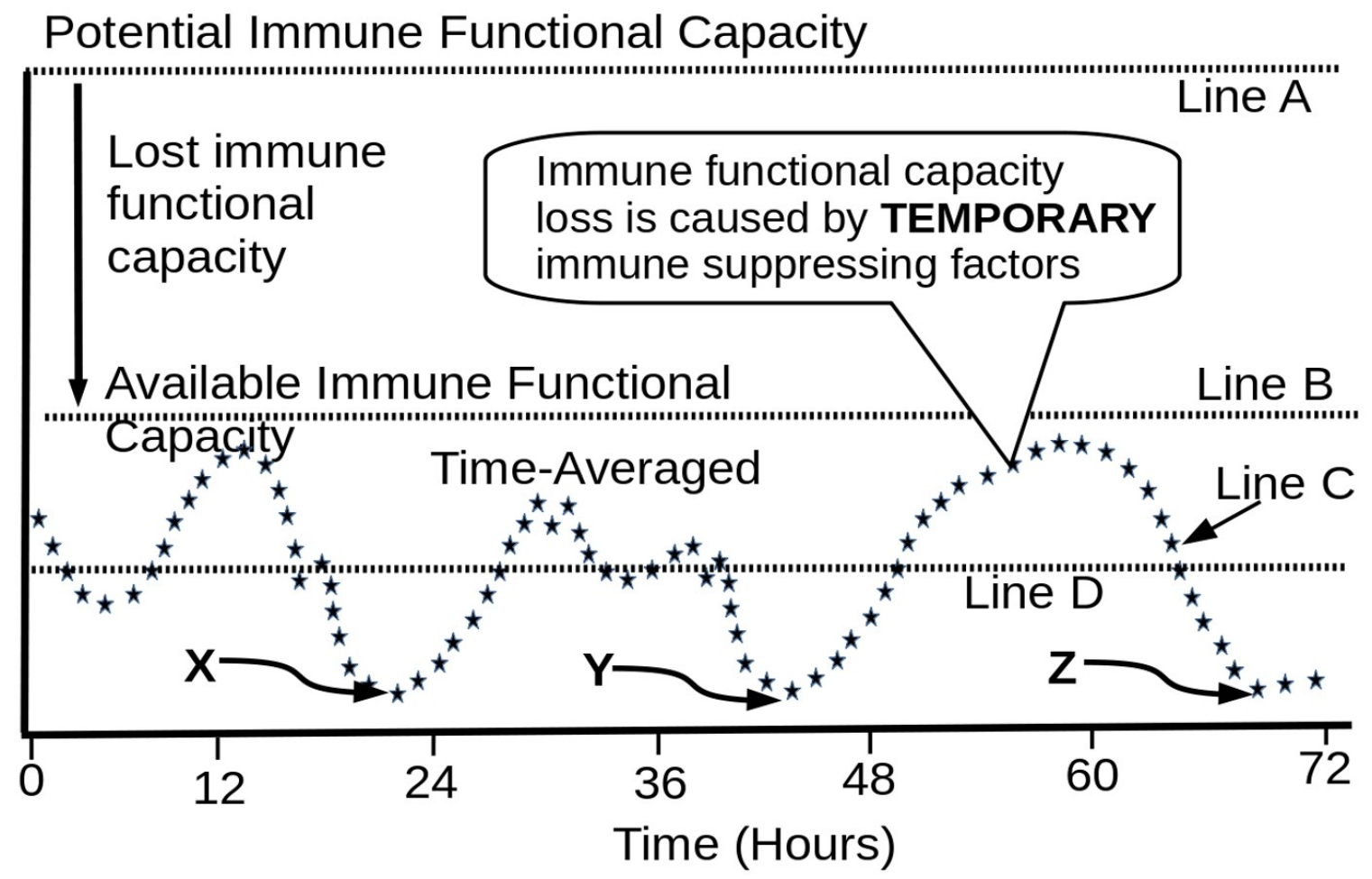

FIG. 3. The Current Immune Functional Capacity of a Person Changes Up and Down in A Short Time Period (3 days). Line C is a hypothetical and arbitrary curve for a hypothetical person. Some factors such as low temperature can depress the immune system immediately, while others such as certain toxic substances and food poisoning may deliver strong adverse effects with a phase delay. It is possible that the immune function may be suppressed at night while toxic substances might be ingested on the day before.

A supplemental figure for illustrating how multiple factors affect the immune system will be available for distribution in the future. 